\title{
Integrating a reproductive health framework within primary care services: The experience of the Reproductive Health Intervention Study [Arabic]
}

Karima Khalil

Abdel Moneim Farag

Assem Anwar

Dina Galal

Olfia Kamal

See next page for additional authors

Follow this and additional works at: https://knowledgecommons.popcouncil.org/departments_sbsr-rh How does access to this work benefit you? Let us know!

\section{Recommended Citation}

Khalil, Karima, Abdel Moneim Farag, Assem Anwar, Dina Galal, Olfia Kamal, Karraze Shorbagi, Miral Breebaart, Hind Khattab, Nabil Younis, and Huda Zurayk. 2000. "Integrating a reproductive health framework within primary care services: The experience of the Reproductive Health Intervention Study [in Arabic]," Policy Series in Reproductive Health. Cairo: Population Council. 


\section{Authors}

Karima Khalil, Abdel Moneim Farag, Assem Anwar, Dina Galal, Olfia Kamal, Karraze Shorbagi, Miral Breebaart, Hind Khattab, Nabil Younis, and Huda Zurayk 


\section{دمج إطار الصحة الإنجابية في خدمات الرعاية الأساسية الأحاية \\ تجربة در اسة تدخل الصحة الإنجابية}

"سلسلة سياسات الصحة الإنجابية"

\begin{tabular}{|c|c|}
\hline \multicolumn{2}{|c|}{ رقم 6} \\
\hline عبد المنعم فرج، طبيب & كريمة خليل \\
\hline أمراض نساء وولادة & ماجستير صحة عامة \\
\hline 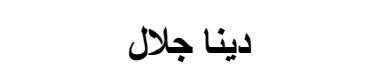 & عاصم أنور، طبيب \\
\hline ماجنتبر صحة عامة & أمراض نساء وولادة \\
\hline نادين كراز شوريجى & ألفيا كمال، ماجستير \\
\hline ماجستير أنثروبولوجيا طبية & اقتصاد و علوم سياسية \\
\hline هند خطاب & ميرال بريبارات \\
\hline دكتوراه أنثروبولوجيا & بكالوريوس علوم الحاسب الآلى \\
\hline هدى زريق، دكتوراه & نبيل يونس \\
\hline إحصاء حبوية & طبيب أمراض نساء وولادة \\
\hline
\end{tabular}

مجموعة بحوث الصحة الإنجابية

المقر

المكتب الإقليم لمجلس السكان بغرب لسيا وشمل أفريقيا 
يسعى مجلس السكان إلى تحسين الرفاهة و الصحة الإنجابية للأجيال الحالية والقادمة فى سائر أنحاء العالم، و المساعدة فى تحقيق توازن إنسانى، عادل ومستدام بين السكان و المو ارد.

وقد تأسس المجلس فى عام 1952 كمنظمة أبحاث غير حكومية لا تسنهدف الربح، ويديره مجلس أمناء متعدد الجنسيات؛ ويدعم مقره الرئيسى فى نيويورك شبكة عالمية من المكاتب الإقليمية و القطرية.

ويتولى إصدار سلسلة سياسات الصحة الإنجابية مجموعة بحوث الصحة الإنجابية ومقر ها المكتب الإقليمى لمجلس السكان بغرب آسيا وشمال أفريقيا، صندوق بريد 115، الدقى، الجيزة، مصر . 


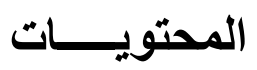

\begin{tabular}{|l|l|}
\hline & \\
\hline & \\
\hline & \\
\hline & \\
\hline & \\
\hline & \\
\hline & \\
\hline & \\
\hline & \\
\hline & \\
\hline & \\
\hline & \\
\hline & \\
\hline & \\
\hline & \\
\hline & \\
\hline & \\
\hline$V$
\end{tabular}

V.

مقدمسـة: سلسلة سياسات الصحة الإنجابية ...

VI

أعضاء فريق دراسة تدخل الصحة الإنجابية .

VII شكر وعرفان

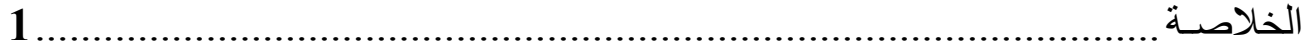

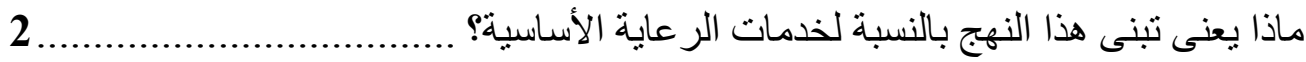

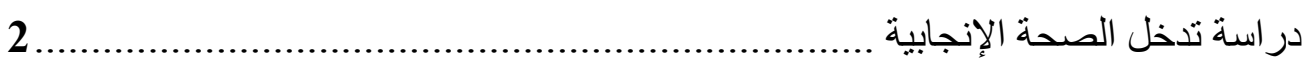

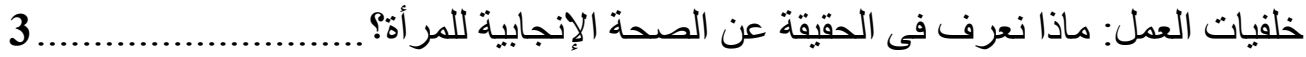

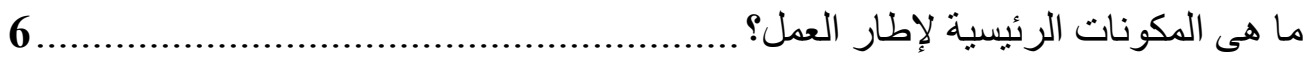

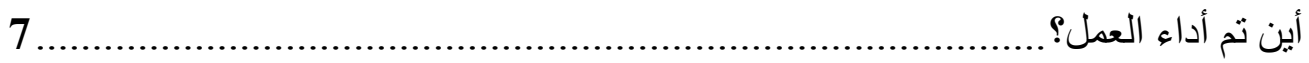

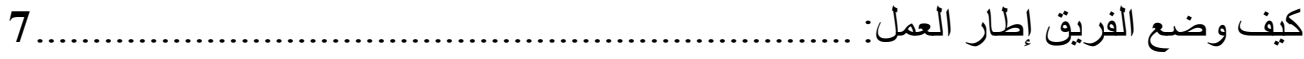




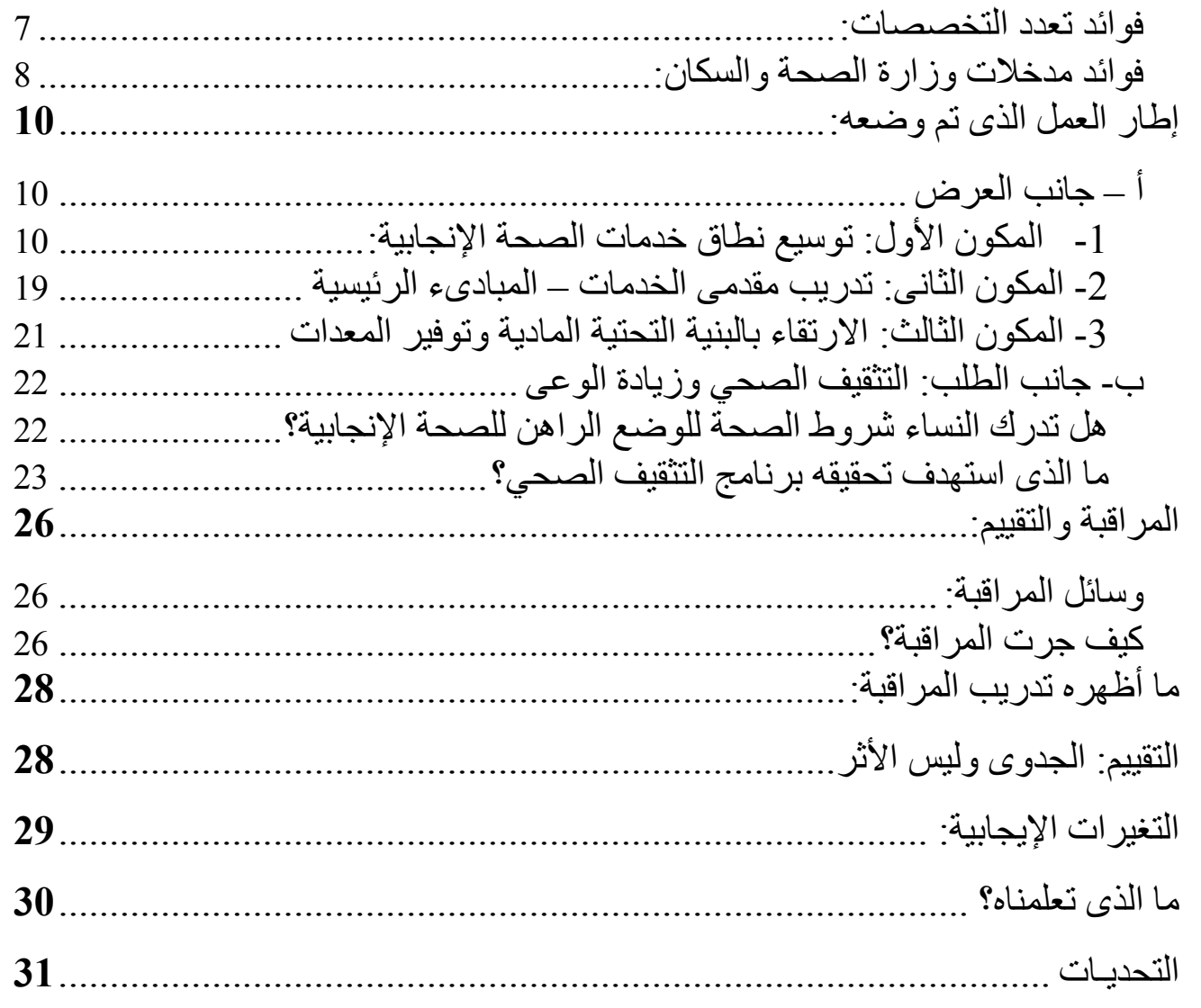

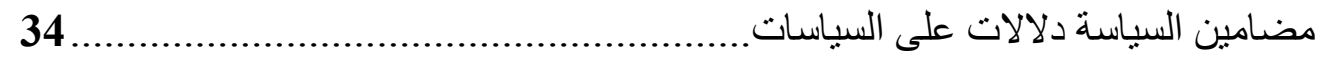

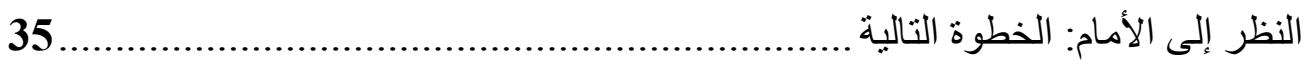

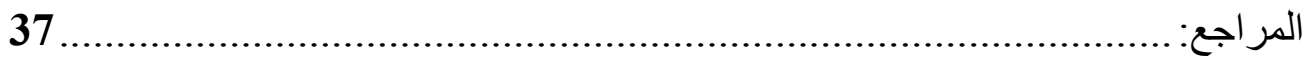

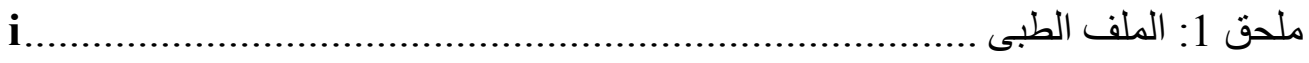




\section{مقدمسة: سلسلة سياسات الصحة الإتجابية}

تهدف الورقات الواردة فى سلسلة سياسات الصحة الإنجابية إلى المشاركة بالدر اسات التى يقوم بها أعضاء مجمو عة بحوث الصحة الإنجابية مع صانعى السياسة، ومديرى البرامج، و المؤيدين لأهمية الرعاية الصحية فى المنطقة، والعالم النامى، والمجتمع الدولى. وقد تكونت مجمو عة بحوث الصحة

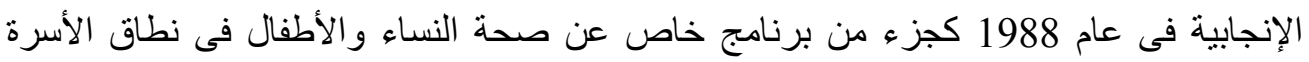
و المجتمع، بدأه المكتب الإقليمى لمجلس السكان بغرب آسيا وشمال أفريقيا. وتضم مجموعة البحوث مهنيين متخصصين فى علوم الأنثروبولوجيا، والإحصاء الحيوية، والسكان، و الطب، و الصحة العامة، و الاجتماع، من المقيمين فى مختلف بلدان المنطقة.

وقد حددت مجموعة البحوث ثلاث قضايا رئيسية تعد قضايا محورية بالنسبة للصحة الإنجابية

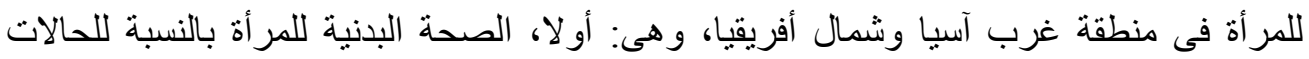
المرضية ذات الصلة بالوظيفة الإنجابية؛ وثانيا، مفاهيم النساء عن حالتهن الصحية وكرامتهن بالنسبة للإنجاب؛ وثالثا، من ناحية الخدمة الصحية، جودة خدمات الصحة الإنجابية الموجهة للنساء. وقد قامت مجمو عة البحوث بإجر اء در اسات تعالج هذه القضايا فى بلدان المنطقة منذ عام 1989.

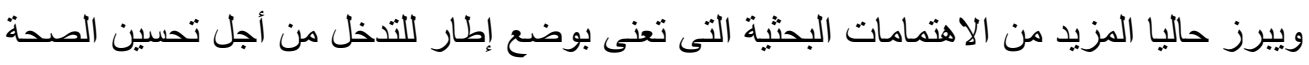

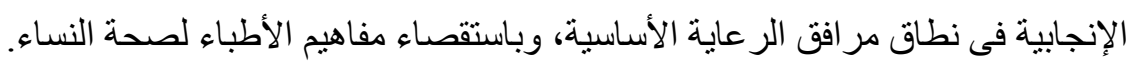

وتعتبر سلسلة سياسات الصحة الإنجابية وسلسلة الرسائل العلمية فى الصحة الإنجابية مجمو عتين متكاملتين من الإصدار ات عن مجموعة بحوث الصحة الإنجابية. وتقدم الرسائل العلمية

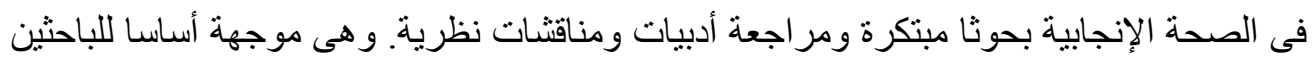
و الدارسين وتهدف إلى الإسهام فى تقدم المناهج متعددة التخصصات فى مجال البحوث الخاصة ودهات

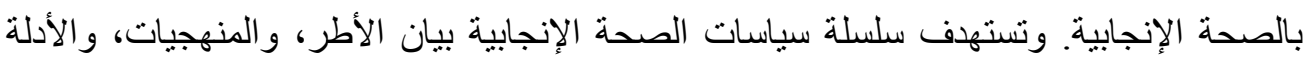

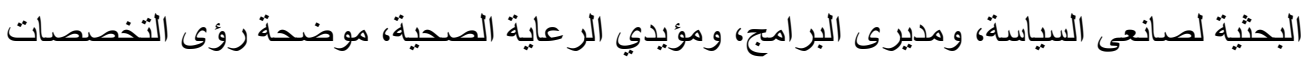

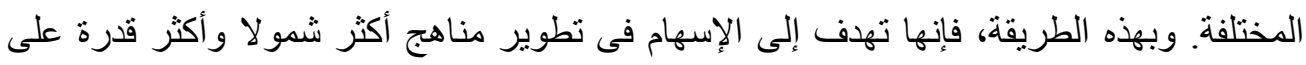
تلبية الاحتياجات الصحية للنساء فى البلدان النامية. 


\title{
أعضاء فريق دراسة تدخل الصحة الإنجابية
}

\author{
دلتا للاستثاريين \\ د. هند خطاب \\ الأستاذة ألفيا كمال \\ الأستاذة نادين كراز شوربجى \\ د. دينا جلال \\ جامعة الأزهر \\ ا.د. نبيل يونس

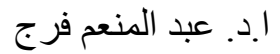

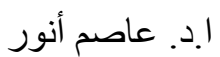 \\ مجلس السكان \\ د. كريمة خليل

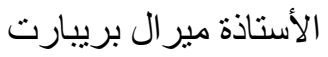 \\ كلية العلوم الصحية ـ الجامعة الأمريكية فى بيروت \\ ا.د. هدى زريق
}




\section{شكر وعرفان}

يود المؤلفون الإشادة بالمشاركة القيمة للباحثين الميدانيين فى دلتا للاستشاريين كجزء من الفريق التنفيذى الذى أجرى الدراسة. ويجدر تقديم الثكر لكل من د. ميرفت الجنيدى وكذلك لمدربات الممرضات نعمت أبو السعود، وبشرى رباب، وصوفى فرج. كما يتعين نوجيه الثكر لفاتن محمد مئد

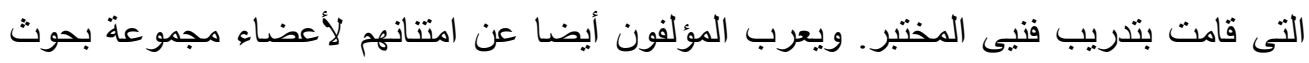
الصحة الإنجابية على إعطائهم الصدى الرجعى خلال تقدم مر احل الدر اسة المختلفة. وقد كان إسهام د. صلاح مو اجده فى تصميم الملفات الطبية بالغ القيمة.

ويقر المؤلفون بفضل التعليقات القيمة التى قدمتها د. سينتيا مينتى على مسودة هذه الورقة. ويودون كذلك تقديم الثكر إلى د. برباره إبراهيم على مساهنها فى التحرير، ونهى جاب الله

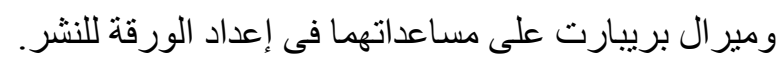

كما يود المؤلفون الإعراب عن تقدير هم لموظفى وزارة الصحة والسكان على المستويات

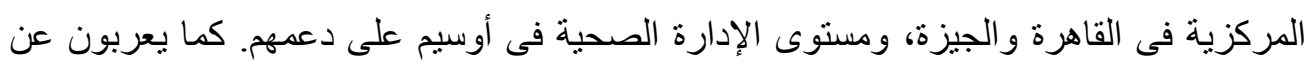

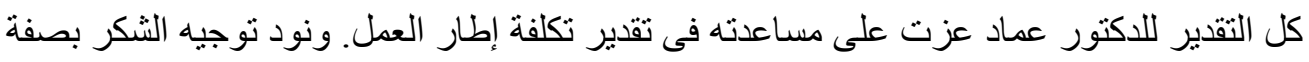
خاصة لمقدمى الرعاية الأساسية الذين تعاونو ا بحماس حقيقى فى تتفيذ إطار العمل.

وقد حظيت دراسة تدخل الصحة الإنجابية بدعم صندوق الأمم المتحدة للسكان، ومجلس

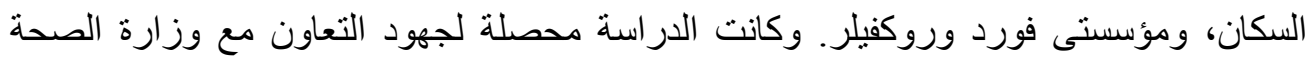
و السكان المصرية. وقد نم إصدار هذه الورقة بفضل المنحة المقدمة من مؤسسة فورد إلى مجموعة ورونة بحوث الصحة الإنجابية. 


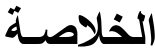

تصف هذه الورقة تجربة دراسة تدخل الصحة الإنجابية. وقد تضمنت الدراسة تصميم واختبار نموذج لخدمات الصحة الإنجابية الضرورية. وحددت إطار آلمكونات الخدمات الأساسية التى تعالج الصحة الإنجابية، وأوضحت أن تقديمها أمر ممكن على المستوى الأساسى. وتهدف هذه الورقة إلى ولى إعطاء صورة شاملة لهذه التجربة، توضح كيفية نرجمة نهج الصحة الإنجابية إلى خطوات لتقديم خدمة فعلية على مستوى الرعاية الأساسية فى نطاق البلدان النامية. وتقدم الورقة الخطوط العامة

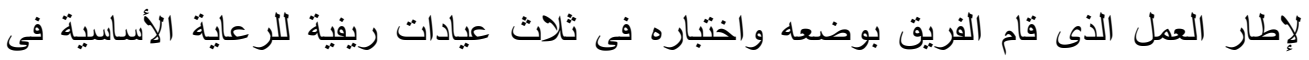

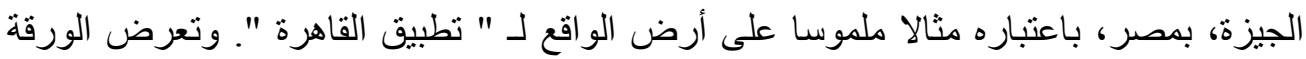
الإنجاز ات الأساسية وكذلك التحديات، وتتاقش أبرز المضامين السياسية.

تعتبر الصحة الإنجابية نهجا جديدا نسبيا. و هى تنشد معالجة صحة النساء بصورة متكاملة، وتتضمن تنظيم الأسرة ومسائل الأمومة، ولكنها لا تقتصر على ذلك فقط. ومن التفسيرات المختلفة المستخدمة حاليا لتعريف الصحة، هنالك اتفاق عام على أنها تتضمن " حالة من السلامة البدنية، والعقلية، والاجتماعية الكاملة، وليس مجرد عدم وجود المرض أو العجز ".(1) وفى هذا السياق، لا تقتصر

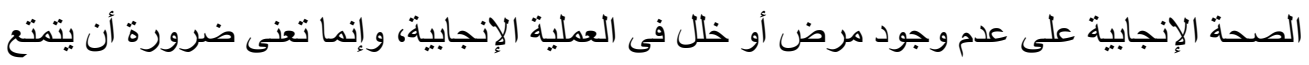
الناس بالقدرة على العيش طو ال سنوات الإنجاب وما بعدها مع خيار الإنجاب، و الكر امة، و السلامة

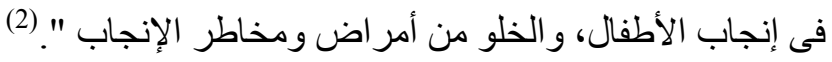

وقد اكتسب هذا النهج قبو لا واسعا منذ المؤتمر الدولى للسكان والتنمية، (3) وهو المنتدى الذى

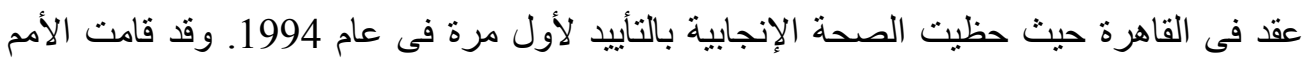
المتحدة، بمناسبة الذكرى الخامسة للمؤتمر الدولى للسكان و التتمية، بإجر اء مر اجعة على مستوى لهره

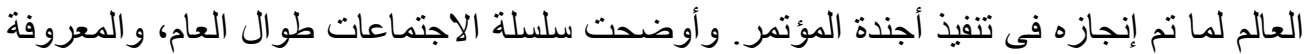
بعبارة "المؤتمر الدولى للسكان و التنمية+5"، أنه رغم التقدم الملحوظ الذى تحقق، فإنه لاتز ال هناك

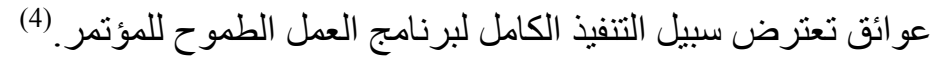




\section{ماذا يعنى تبنى هذا النهج بالنسبة لخدمات الرعاية الأساسية؟}

يعتبر هذا النهج جديدا ومثير اللتحدى من نواحى كثيرة. ذلك أن تبنيه يعنى أن على مر افق الخدمات

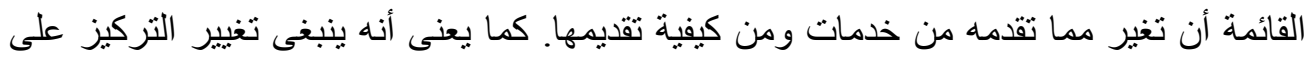

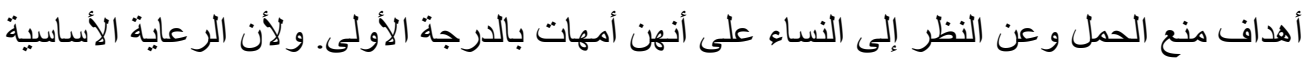

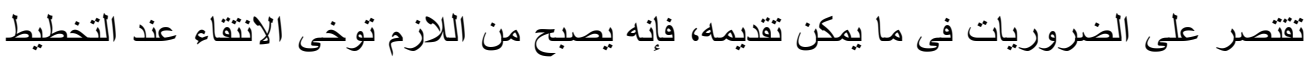

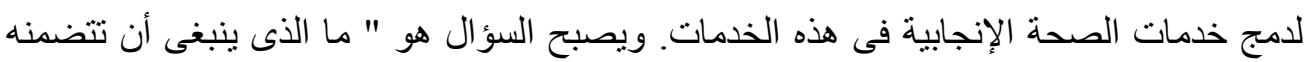
الخدمات الأساسية للصحة الإنجابية؟ ".

وقد حاولت دراسة تدخل الصحة الإنجابية التى تناولتها هذه الورقة الإجابة عن هذا السؤال. وقامت بتصميح واختبار نموذج للخدمات التى يمكن ملاءمتها للتطبيق على نطاق أوسع فى مصر لإنه و غيرها. وحددت الدراسة إطارا لمكونات الخدمة الأساسية التى تتصدى للصحة الإنجابية، وأوضحت أن تقديمها أمر ممكن على المستوى الأساسى. وتهدف هذه الورقة إلى إلقاء نظرة عامة على هذه التجربة، التى توضح كيف يمكن ترجمة نهج الصحة الإنجابية إلى و اقع عند تقديم الخدمة على مستوى الرعاية الأساسية، فى محيط دولة نامية. وتلخص الإطار الذى قام الفريق

بوضعه و اختباره فى ثلاث عيادات ريفية للرعاية الأساسية فى الجيزة، بمصر ، التى تعتبر مثالا

$$
\text { ملموسا على أرض الو اقع لـ " تطبيق القاهرة ". }
$$

\section{دراسة تدخل الصحة الإنجابية}

أجرت هذه الدراسة مجموعة منبثقة عن مجموعة بحوث الصحة الإنجابية، (5) التى تعاونت مع باحثين آخرين لتشكيل فريق دراسة تدخل الصحة الإنجابية. وقد تكون الفريق من عالم

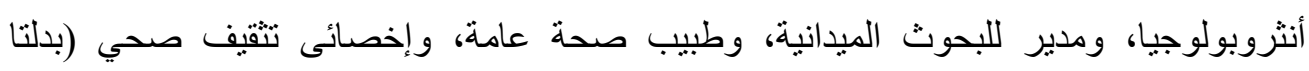

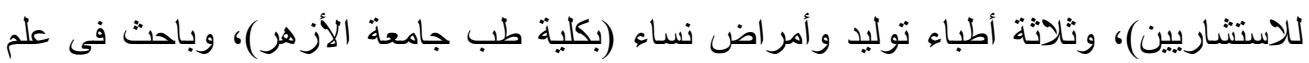
السكان والإحصاء الحيوية، وطبيب صحة عامة، وباحث مساعد (بمجلس السكان). وقام الفريق وند

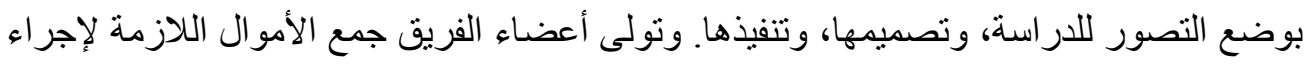

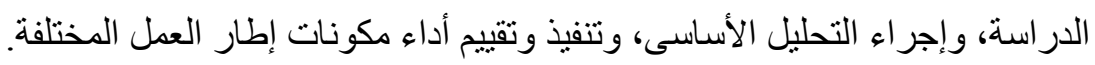

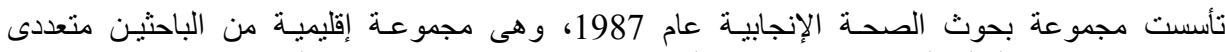

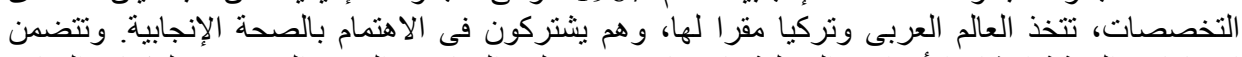

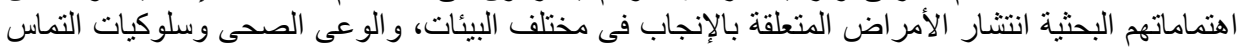

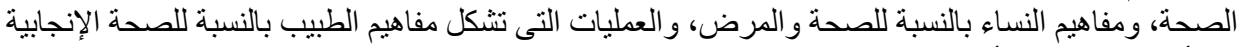

للمر أة، وموضو عات ومفئ أخرى. 
وقد كانت هذه الدر اسة ثمرة لتضافر الجهود مع وزارة الصحة والسكان المصرية، وقد تلقت دعما من جانب صندوق الأمم المتحدة للسكان، ومجلس السكان، ومؤسستى فورد وروكفيلر. وقد ورد وصف تفصيلى لمختلف مكونات إطار العمل فى ورقات وكتيبات منفصلة.

\section{خلقيات العمل: ماذا نعرف فى الحقيقة عن الصحة الإنجابية للمرأة؟}

نشأ اهتمام الفريق بوضع إطار للخدمات الأساسية للصحة الإنجابية انطلاقا من عمل سبق للفريق تنفيذه على مستوى المجتمع، فى ريف الجيزة أيضا. وقد أوضح هذا البحث، الذى أصبح الصنح يعرف عامة باسم در اسة الجيزة، أن النساء كان مستوى الإصابة لديهن بأمر اض النساء و غيرها من

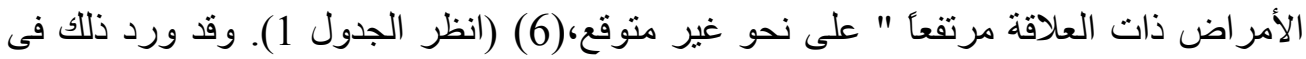
دراسات عديدة أخرى(7) فى أماكن أخرى من العالم. والحقيقة أن حالات مثل التهابات الجهاز التناسلى وجد أنها شائعة كثير ا فى أغلب البلدان النامية التى تناولتها الدراسات بالبحث.(8) وقد ماته دفعت مثل هذه النتائج الفريق إلى دراسة الفجوة القائمة بين عبء المرض وضده والخدمات التى تتو افر للنساء فى مر افق خدمات الرعاية الأساسية. وقد تطابقت اهنمامات الفريق مع الاهتمام العالمى(9) الذى نما مع المؤتمر الدولى للسكان والتتمية، لتحديد كيفية تحقيق تطوير أفضل للخدمات الأساسية

$$
\text { لتعكس نهج الصحة الإنجابية. }
$$

جدول 1 النسبة المئوية لانتشار الحالات المرضية الرئيسية المكتشفة، عن يونس وآخرين.

\begin{tabular}{|c|c|}
\hline$\%$ & الحالـة \\
\hline 51 & عدوى الجهاز \\
\hline 44 & التهاب المهبل(') \\
\hline 22 & الالتهاب المهبلى البكتيرى \\
\hline 18 & الترايكوموناس \\
\hline 11 & الكانديدا \\
\hline 10 & التهاب عنق الرحم(ب) \\
\hline 2 & مرض التهاب الحوض(ب) \\
\hline
\end{tabular}

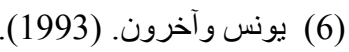

(7) فاسر هايت (1989) )، شودرى (1989) ، آخرون (1995)، حسين و آخرون (1996).

(8) فاسر هايت (1989)، ام. الى. خان (1998)، (1998).

(9) باتثـوارى (1995)، هاردى ويونت (1995)، (1995)، فورتنى (1995)، إلياس (1996)، هاردى وآخرون (1999)،

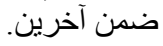




\begin{tabular}{|c|c|}
\hline$\%$ & الحالـة \\
\hline 22 & خروج عنق الرحمباتتبّاز/ بروز بطانة عنق الرحم(ب) \\
\hline 11 & (تغيرات مريبة فى خلايا عنق الرحم() \\
\hline 56 & سقوط الأعضاء التناسلية"(ب) \\
\hline 27 & السقوط المهبلى الخلفى أو الأمامى \\
\hline 21 & السقوط الدهبلى الخلفى و الأمامى \\
\hline 8 & السقوط المهبلى والرحمى \\
\hline 14 & عاوى المسالك البولية)(1) \\
\hline 1 & 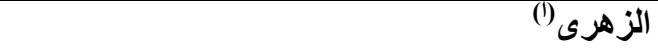 \\
\hline 63 & فقتر اللام (الأنيميا) (هو جلوبين >12جم/ دل) (1) \\
\hline 43 & البدانة (الوزن/ الطول>2 25$)$ \\
\hline 18 & ارتفاع ضغط الدم (انبساطى > 90) (ب) \\
\hline 502 & عدد النساع(ج) \\
\hline
\end{tabular}

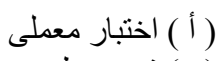

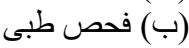

(ج) تغييت بعض النساء فى كل حالة، ولذلك يتم بيان متوسط عدد النساء لجميع الحالات. 
الثكل 1: إطار مبسط لاراسة تدخل الصحة الإنجابية

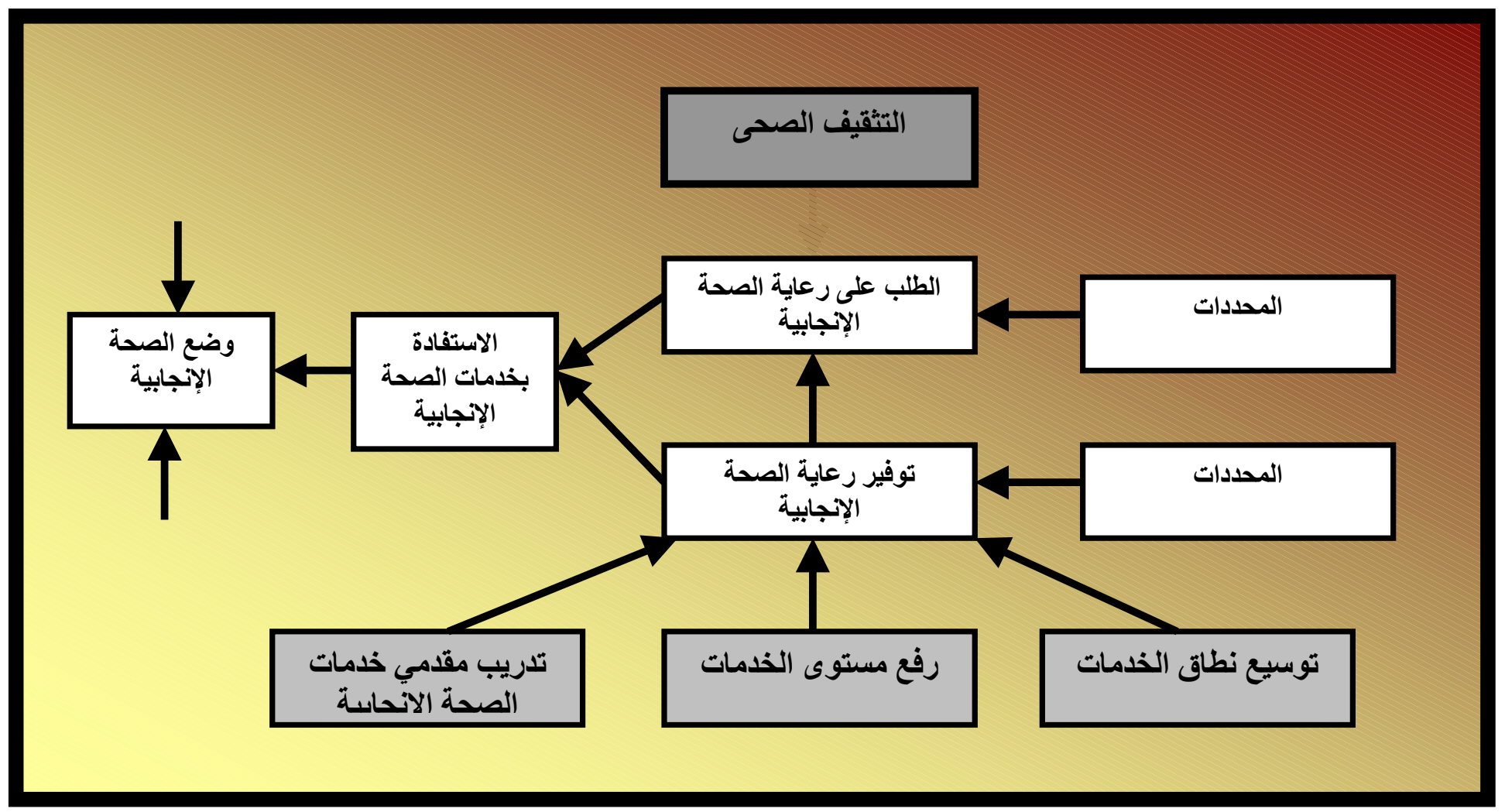




\section{ما هى المكونات الرئيسية لإطار العمل؟}

يوضح الثكل 1 الإطار الفكرى لاراسة التدخل. ويمثل وضع الصحة الإنجابية للسكان فى الصى الإطار الخانة بعنوان "وضع الصحة الإنجابية"، فى أقصى يسار الرسم البيانى. ومع إدراك أن الن النح

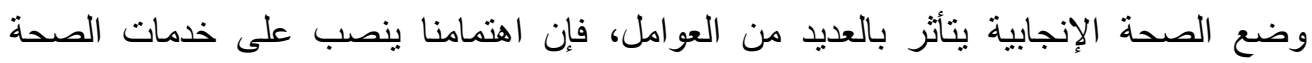
الإنجابية المتاحة و على العوامل التى تؤثر على استيعاب الانتفاع بالخدمة. وتعتبر الاستفادة من لهن الخدمات بالدرجة الأولى نتاج عاملين اثثين هما: الطلب على الرعاية وتوفيرها. وهما ينأثران

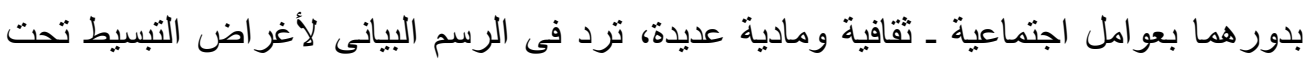

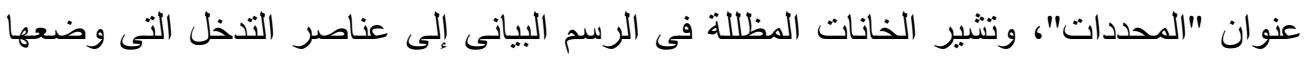

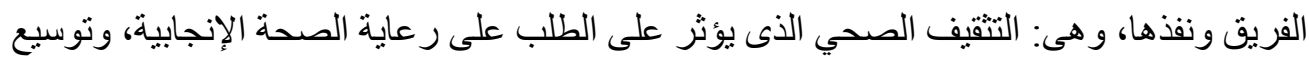

$$
\text { نطاق الخدمات ورفع مستو اها، وتدريب مقدمى الخدمات بهدف توفير ها. }
$$

$$
\begin{aligned}
& \text { ما هى الأهداف الرئيسية للاراسة؟ } \\
& \text { أولا - من ناحية العرض: }
\end{aligned}
$$

التوسع فى خدمات الصحة الإنجابية المتاحة فى المراكز الصحية. ويتضمن ذللك،

كما سيرد أدناه، توسيع نطاق ما كان يجرى تقديمه ليشمل خدمات جديدة، ودمج المكونات المختلفة للخدمات، ومراقبة الجودة، ودعم التنظيم والإدارة، والخدمات

$$
\text { الميدانية والإحالة؛ وأخيرا، تأكيد استمر ار الإمدادات. }
$$

(ب) تنفيذ عملية الارتقاء بالبيئة المادية لملائمة هذا المستوى من الرعاية بتكلفة

منخفضة.

(ج) تدريب مقدمى الخدمات لاكتساب المهار ات فى النواحى الفنية ومهار ات التو اصل.

ثانيا - من ناحية الطلب، تنفيذ برنامج تثقيفى لزيادة الوعى الصحى للمجتمع من رجال

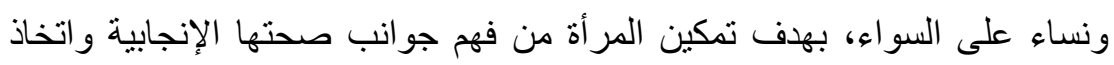

$$
\text { القرار ات بشأنها. }
$$

ثالثا - تطوير مؤشرات ملائمة ووسائل للتقييم تكون قادرة على مر اقبة أداء عناصر

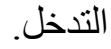

$$
\text { رابعا - نقل الدروس المستفادة إلى وزارة الصحة و السكان. }
$$




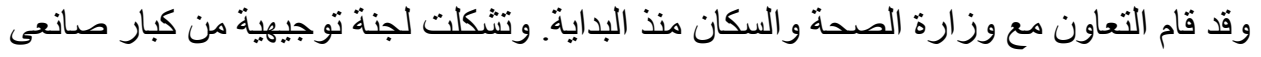

السياسة فى الإدارات المعنية. وكانت اللجنة تتعقد دوريا" "لمر اجعة التقدم الذى يتم إحرازه واتخاذ القرار ات بشأن أنشطة المشروع. وقد نتج إطار الخدمات الذى تمت صياغته فى نهاية الأمرعن هذا

الجهد الجماعى.

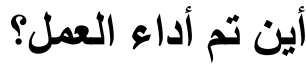

توجد مر اكز الر عاية الأساسية الثناثة التى حددها فريق الدراسة لتنفيذ إطار العمل، فى الجيزة، على بعد 20 إلى 40 كيلومترا من القاهرة. وتعتبر هذه المراكز جزءا من التغطية القومية للرعاية

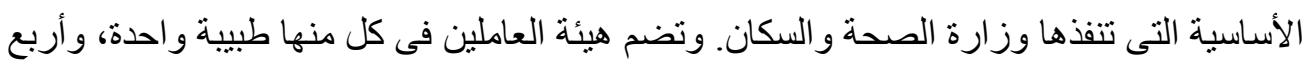
ممرضات فى المتوسط، وفنى مختبر، ومشرفا، ومسجلا، ومعاون صحة. وتقوم المر اكز بصورة روتينية بعمليات تطعيم الأطفال و علاج الحالات البسيطة. وفيما يتعلق بالخدمات الخاصة بالمر أة، وهات تركز هذه المر اكز بصفة أساسية على تقديم خدمات تنظيم الأسرة، مع وجود خدمات ما قبل الو لادة وما بعدها، نظريا فى أغلب الأحيان وليس فى الواقع. ويقارن الجدول 2 إطار الخدمة الذى تقترحه الدراسة مع ما كان يجرى تقديمه على المستوى الأساسى قبل التدخل. وتحظى الخدمات فى هذه الهـ المر اكز بدعم مكثف من جانب الحكومة. وفى الصباح، يطلب من المريض شر اء تذكرة بمبلغ جنيه مصرى واحد، (10) فى مقابل الفحص الطبى وصرف الدواء مجانا. و يرتفع هذا الرسم إلى 3 جنيهات بعد الساعة 11 صباحا، و يحق للطبيب فرض الرسوم التى يقرر ها بدءا من الساعة الو احدة

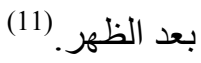

\section{كيف وضع الفريق إطار العمل:} فوائد تعدد التخصصات:

قام الفريق بدر اسة كافة نواحى تقديم الخدمات فى المر اكز الصحية على مدى فترة استمرت عدة شهور فى بداية الدراسة. كما نظر بعمق فى أنماط وتوجهات واتجاهات الاستفادة من الرعاية الصحية فى المجتمع. وقد تم وضع جميع هذه المسائل فى الاعتبار عند صياغة إطار الخدمات. وقد استغرقت عملية وضع إطار العمل وتقرير أى من المكونات يتضمنه أو لا يتضمنه الإطار

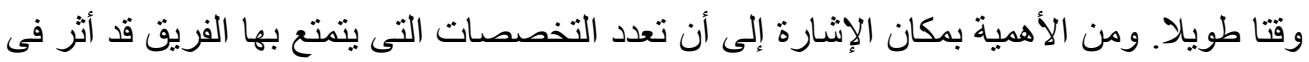
هذه العملية إلى حد كبير. وكان الفريق المكون من علماء اجتماع، و أطباء ممارسين، وخبير إحصاء حيوية، وأطباء صحة عامة، يلتقى أسبوعيا كمجموعة طوال الفترة التى استغرقتها الدراسة. وتم

(10) الجنيه المصرى بساوى 30 سنتا أمريكيا. (11) تم استحداث هذا النظام لتشجيع الأطباء على العمل فى المناطق الريفية. 
اتخاذ جميع القرارات كفريق واستفاد الإطار النهائى من مساهمة كل عضو على أساس تخصصه أو تخصصها.

وقد قدم علماء الاجتماع، على سبيل المثال، خبراتهم فى المناقثات حول المكونات الطبية

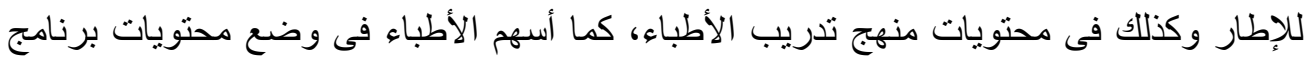
التثقيف الصحى. كذللك تم تصميم ومراجعة وسائل المسح القاعدى الأساسى، والوسائل التئل التى تم وضعها خصيصا لأغراض المراقبة والتقييم، بواسطة الفريق ككل، حيث أضاف كل عضو بطبيعة الحال خلفيته أو خلفيتها فى تفسير النتائج التى تم التوصل إليها. فوائد مدخلات وزارة الصحة والسكان: استفادت عملية وضع إطار العمل بقدر كبير من مدخلات موظفى وزارة الصحة والسكان على ولى الصان المستويات المركزية ومستويات الإدارات والوحدات الصحية. وقد راجعت اللجنة الصنة التوجيهية

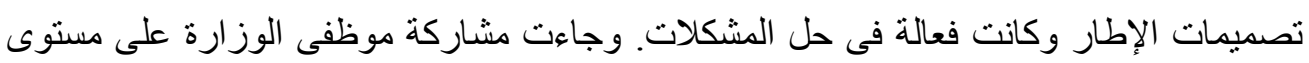

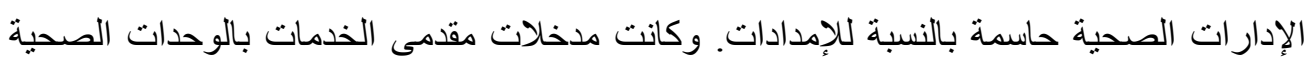
بشأن العناصر التى يمكن تقديمها على هذا المستوى من الرعاية بالغة الأهمية بالنسبة للعملية. 
جدول 2: مقارنة الخدمات السابقة مع الإطار الموسع لتوفير الخدمات الذى اختبره الفريق(12)

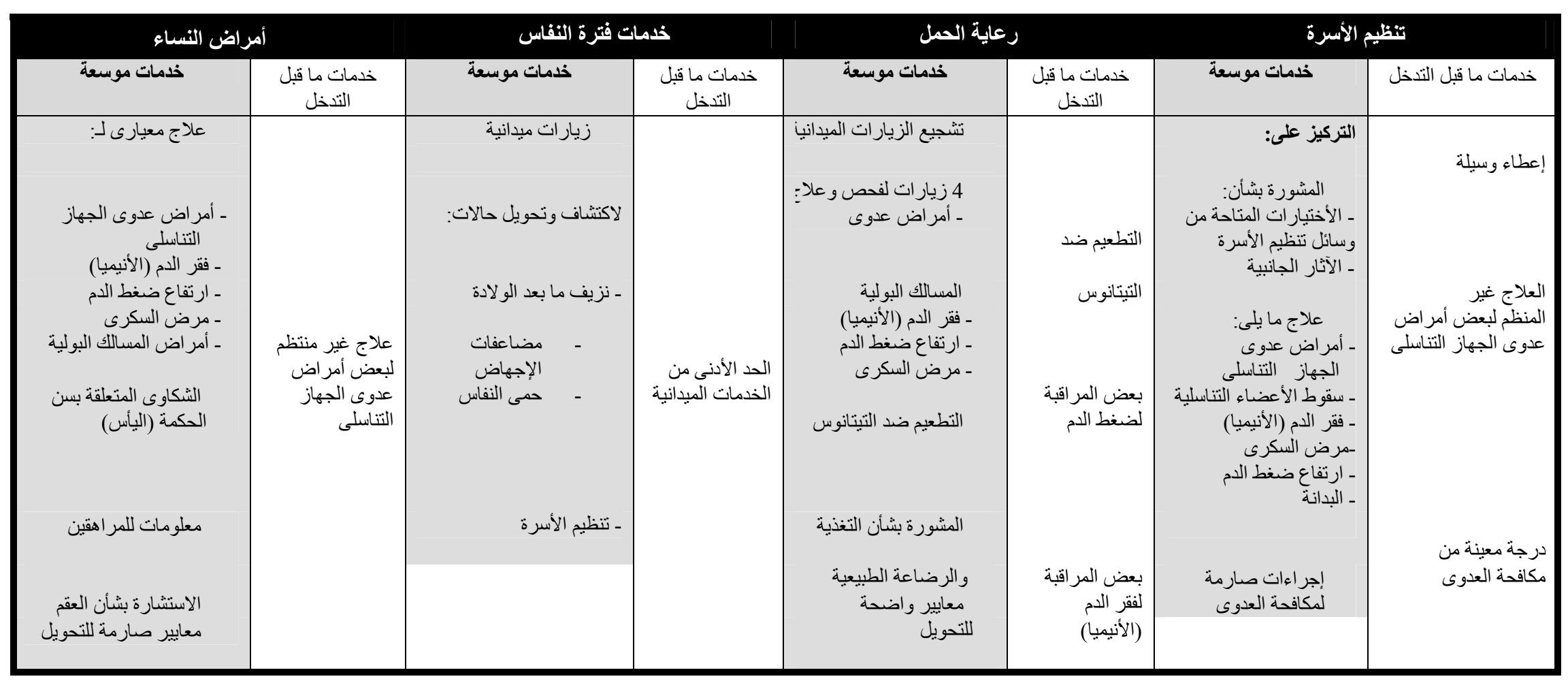

(12) تفاصيل تقديم الخدمات لاحقة فى جداول منفصلة. 


\section{إطار العمل الأى تم وضعه:}

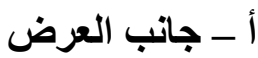

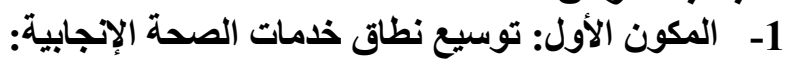

1-1 توفير ما ينقص: توسيع نطاق الخدمات المتاحة من أجل المعالجة الأفضلتلبيه أفضل

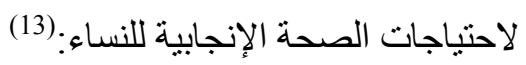

أجرى الفريق مسحا قاعديا" أظهر أن الخدمات الأساسية التى تقدمها العيادات للنساء

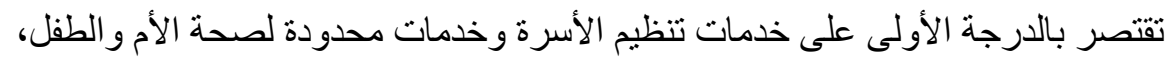

كما يتضح فى الجدول 2.

وتعتبر خذمات تنظيم الأسرة جزء \&" من برنامج نشيط يجرى تمويله رأسيا، وكان يركز

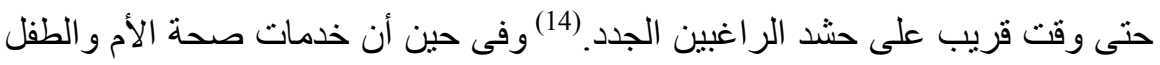

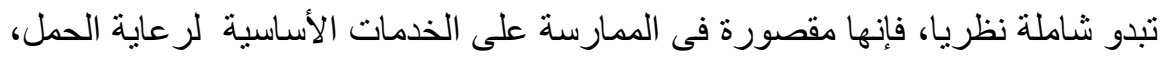

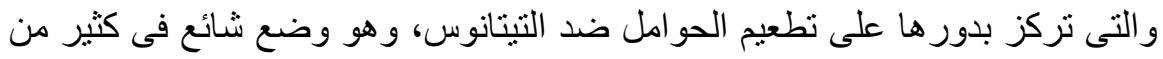
البلدان النامية. وليست هناك خدمات منظمة مناحة لثنكاوى أمر اض النساء النساء البسيطة. ويتضح عند مقارنة هذه الأنثطة بعبء الأمر اض الموثقة فى تلك المجتمعات أن هناك الكاك

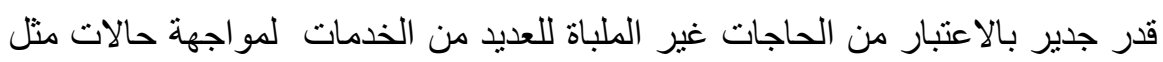

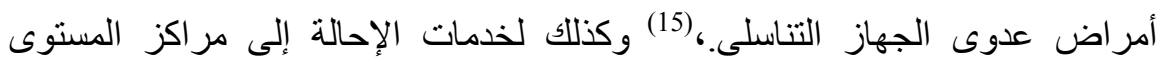
الثانوي للخدمة للحالات الأكثر تعقيدا مثل الحالات المتقمة لسقوط الأعضاء التتاسلية

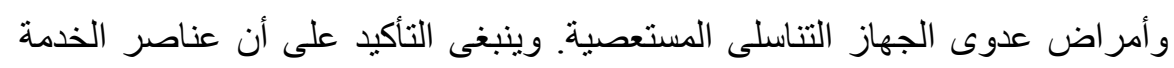

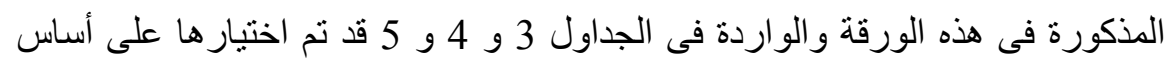
مدى ملاءمتها لمرفق فى مستوى الرعاية الأساسية.

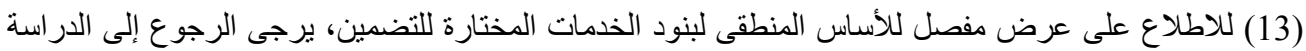
المتاحة لهجموعة بحوث الصحة الإنجابية حول إطار المكونات الطبية ليونس وآخرين (2000).

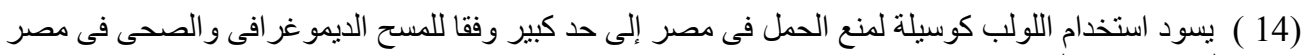

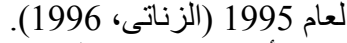

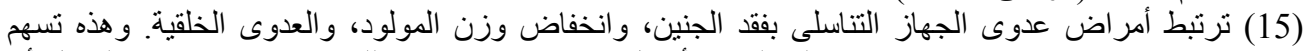

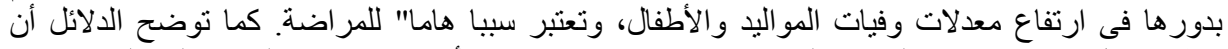

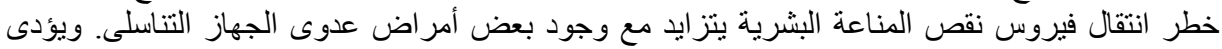

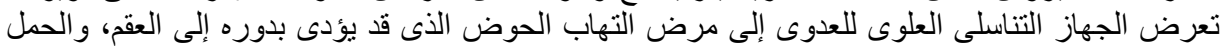

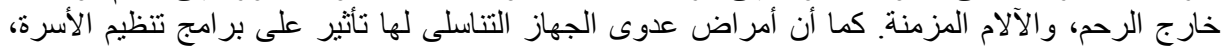

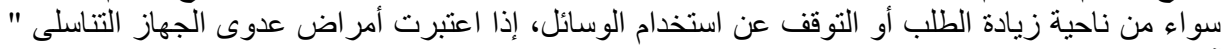

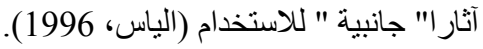




\section{خلمات رعاية الحمل وفترة النفاس}

ركز الفريق اهتمامه على الخدمات الضرورية لرعاية الحمل والتى يمكن تقديمها على في هذا المستوى، وهى موضحة فى الجدول 3. و لا تجرى عمليات الو لادة فى مر افق الرعاية الفي الأساسية،

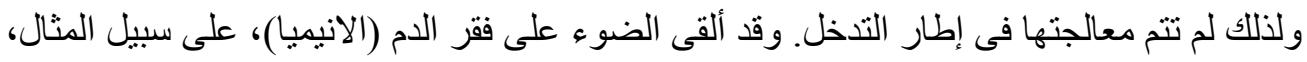

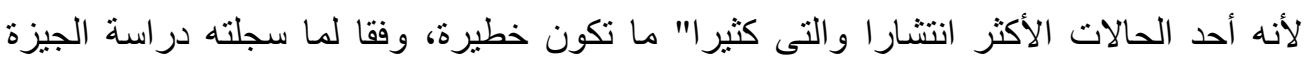

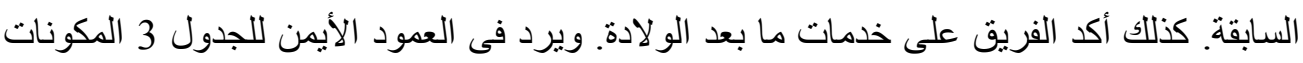

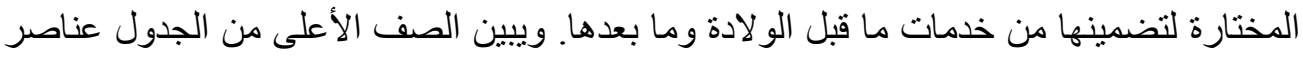
الخدمات التى يمكن توفير ها لكل مكون مختار ، على في هذا المستوى من الخدمات الصحية. 
جدول 3: عناصر خدمات رعاية الحمل وفترة النفاس المختارة لتضمينها فى إطار العمل

\begin{tabular}{|c|c|c|c|c|c|c|c|c|}
\hline الإمدادات & التحويل & الميا(نية & المشورة & الأدوية & المعدات & المختبر* & الطبى & \\
\hline & & $\mathrm{X}$ & $\mathrm{X}$ & & & & & رعاية الحمل \\
\hline $\mathrm{X}$ & $\mathrm{X}$ & & $\mathrm{X}$ & $\mathrm{X}$ & $\mathrm{X}$ & $\mathrm{X}$ & $\mathrm{X}$ & فحص و علاج أمر اض عدوى الجهاز التناسلى \\
\hline $\mathrm{X}$ & & $\mathrm{X}$ & & $\mathrm{X}$ & & & & مصل التيتانوس \\
\hline \multirow[t]{2}{*}{$\mathrm{X}$} & $\mathrm{X}$ & & $\mathrm{X}$ & $\mathrm{X}$ & $\mathrm{X}$ & $\mathrm{X}$ & $\mathrm{X}$ & مسح لأكتشاف و علاج فقر الدم (الأنيميا) \\
\hline & $\mathrm{X}$ & & $\mathrm{X}$ & (16)! & $\mathrm{X}$ & & $\mathrm{X}$ & مسح لأكتثاف و علاج ارتفاع ضغط الدم \\
\hline $\mathrm{X}$ & $\mathrm{X}$ & & $\mathrm{X}$ & & $\mathrm{X}$ & $\mathrm{X}$ & $\mathrm{X}$ & أمر اض عدوى المسالك البولية \\
\hline \multirow[t]{5}{*}{$\mathrm{X}$} & $\mathrm{X}$ & & $\mathrm{X}$ & (17)的 & $\mathrm{X}$ & $\mathrm{X}$ & $\mathrm{X}$ & مسح لأكتثاف و علاج مرض السكرى \\
\hline & & & $\mathrm{X}$ & & & & & النصائح الغذائية \\
\hline & $\mathrm{X}$ & & & & & & $\mathrm{X}$ & نزيف ما قبل الو لادة \\
\hline & & $\mathrm{X}$ & $\mathrm{X}$ & & & & & فترة النفاس \\
\hline & $\mathrm{X}$ & $\mathrm{X}$ & & & & & $\mathrm{X}$ & نزيف ما بعد الو لادة \\
\hline $\mathrm{X}$ & $\mathrm{X}$ & & $\mathrm{X}$ & $\mathrm{X}$ & $\mathrm{X}$ & & $\mathrm{X}$ & مضاعفات الإجهاض \\
\hline $\mathrm{X}$ & $\mathrm{X}$ & $\mathrm{X}$ & & $\bar{X}$ & & & $\mathrm{X}$ & حمى النفاس \\
\hline $\mathrm{X}$ & & $\mathrm{X}$ & $\mathrm{X}$ & $\bar{X}$ & $\mathrm{X}$ & $\mathrm{X}$ & $\mathrm{X}$ & خدمات تنظيم الأسرة \\
\hline
\end{tabular}

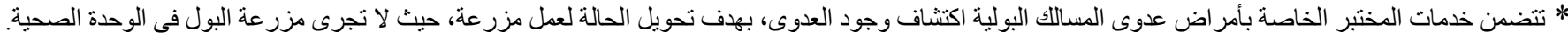
? تثير إلى أنه بالر غم من توصية الفريق، فإن قرار التضمين فى الذدمات القومية هو فى نهاية الأمر قرار يتوقف على الميز انية من جانب الوزارة، بسبب تكاليف هذا العلاج. 


\section{خدمات أمراض النساء والثكاوى ذات العلاقة:}

حيث أن الخدمات الخاصة بحالات أمر اض النساء البسيطة لم تكن متوفرة على في هذا المستوى من

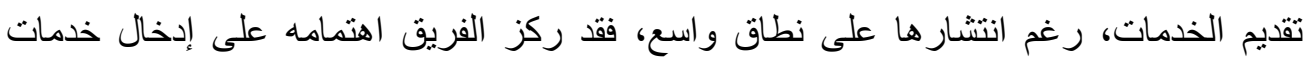

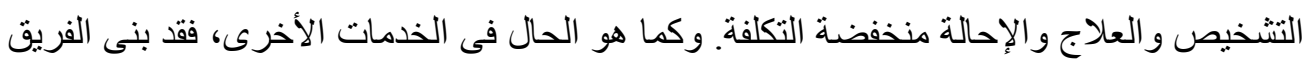
اختياره للحالات التى يتم علاجها على أساس ما دلت دراسة الجيزة السابقة على شيوعه فى هي المجتمع. ولذلك تتضمن الخدمات المختارة تتخيص و علاج عدوى أمر اض الجهاز التناسلى الأكثر شيو عا (مثل المونيليا و التريكوموناس)، و التشخيص و الإحالة بالنسبة لسقوط

الأعضاء التناسلية، وتقديم المشورة والإحالة إذا لزم الأمر بالنسبة للعق. (18) ويورد الجدول 4 عناصر الخدمات الإرشادية لمعالجة كل نوع من الحالات. وتشير علامة الاستفهام فى خانة الأدوية الخاصة بارتفاع ضغط الدم ومرض السكرى إلى أنه ينصح بتوفير ها ولكن ذلك يتوقف في نهاية الأمر على ما تسمح به ميز انية العيادات.

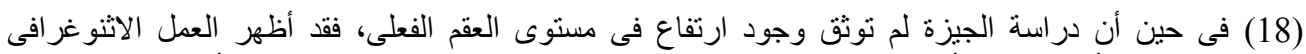

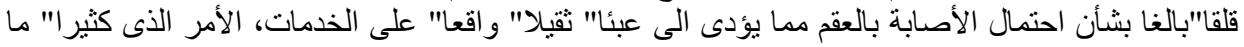

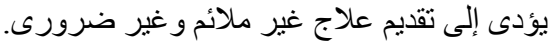


جدول 4: عناصر خدمة أمراض النساء المختارة لتضمينها فى إطار العمل

\begin{tabular}{|c|c|c|c|c|c|c|c|c|}
\hline الإمدادات & التحويل & الميانمية & المشورة & الأدوية & المعدات & ل لمختبر" & الطبى & \\
\hline $\mathrm{X}$ & عند الحاجة & & $\mathrm{X}$ & $\mathrm{X}$ & $\mathrm{X}$ & $\mathrm{X}$ & $\mathrm{X}$ & أمراض عدوى الجهاز التتاسلى \\
\hline $\mathrm{X}$ & $\mathrm{X}$ & & $\mathrm{X}$ & & $X$ & $* \mathrm{X}$ & $\mathrm{X}$ & أمراض عدوى المسالك البولية \\
\hline \multirow[t]{2}{*}{$\mathrm{X}$} & $\mathrm{X}$ & & $\mathrm{X}$ & $?$ & $\mathrm{X}$ & $\mathrm{X}$ & $\mathrm{X}$ & مرض السكرى \\
\hline & عند الحاجة & & $\mathrm{X}$ & & & & $\mathrm{X}$ & سقوط الأعضاء التتاسلية \\
\hline \multirow[t]{3}{*}{$\mathrm{X}$} & عند الحاجة & & $\mathrm{X}$ & $\mathrm{X}$ & $\mathrm{X}$ & $\mathrm{X}$ & $\mathrm{X}$ & فقر الام (الأليميا) \\
\hline & $\mathrm{X}$ & & $\mathrm{X}$ & $?$ & $\mathrm{X}$ & & $\mathrm{X}$ & ارتفاع ضغط الدم \\
\hline & عذد الحاجة & & $\mathrm{X}$ & & & & $\mathrm{X}$ & شكاوى انقطاع الحيض \\
\hline \multirow[t]{2}{*}{$\mathrm{X}$} & عذد الحاجة & & $\mathrm{X}$ & $\mathrm{X}$ & & $\mathrm{X}$ & فى حالة الطلب & خدمات للمراهقين \\
\hline & $\mathrm{X}$ & & $\mathrm{X}$ & & $\mathrm{X}$ & $\mathrm{X}$ & $\mathrm{X}$ & 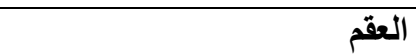 \\
\hline
\end{tabular}

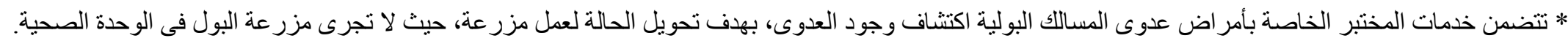
؟ تثير إلى أنه بالرغم من توصية الفريق، فإن قرار التضمين فى الخدمات القومية هو فى نهاية الأمر قرار يتوقف على الميز انية من جانب الوزارة، بسبب تكاليف هذا العلاج. 


\section{خدمات تنظيم الأسرة}

روعى عدم ازدواج الخدمات الناجحة لتنظيم الأسرة التى توفرها وزارة الصحة والسكان بالفعل. ولذلك ركزت الدر اسة على ثلاثة بنود هى: المشورة، والفحص المسحى(انظر جدول 5)، ومكافحة العدوى. ويوضح الجدول 5 مكونات الخدمات اللازمة لكل نو لوع من الأنشطة.

توسيع نطاق الكفاءة الفنية لمقدمى الخدمات لتوفير خدمات متعددة:

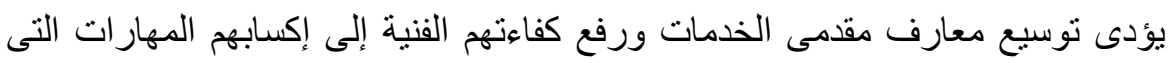

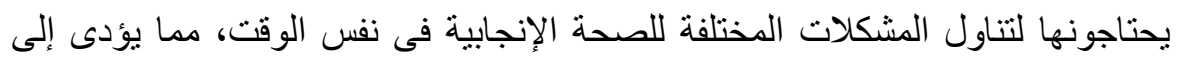

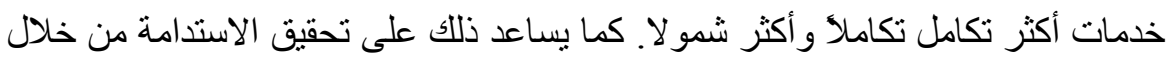
تأمين استمرارية الخدمات فى حالة تغير الموظفين. غير أنه يتعين مراعاة عدم تحميل

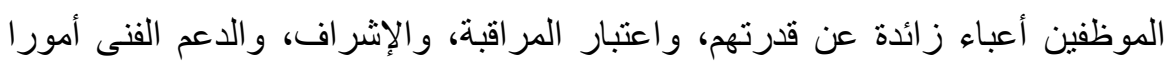

$$
\text { ضرورية. }
$$

\section{قيمة السجلات الطبية البسيطة والثاملة}

وجد الفريق أن الخدمات المختلفة المقدمة في مركز الرعاية الأساسية كانت غير متكاملة

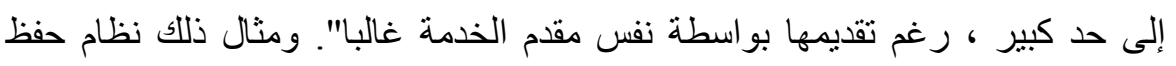
السجلات الذى يتم به حفظ سجلات صحة الأم والطفل وخدمات تنظيم الأسرة، ويحتفظ بكل منها على حدة، عادة فى غرف مختلفة داخل المركز الصحى. ويعتبر ذلك انعكاسا

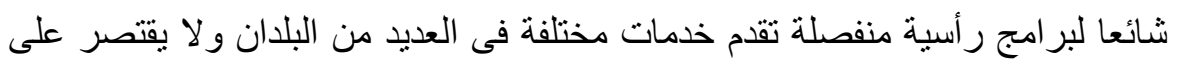

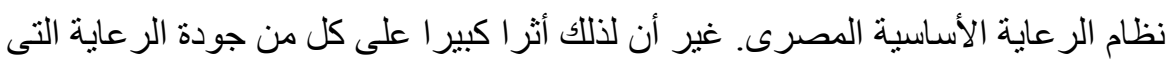

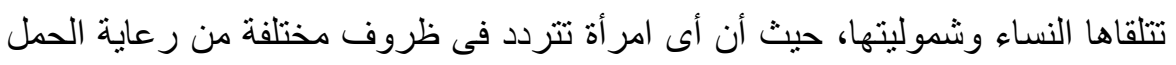

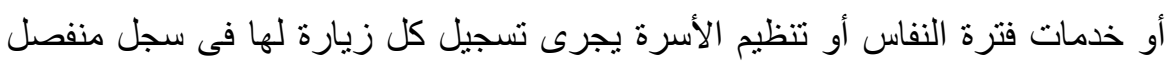
ومكان منفصل. و علاوة على ذلك، فإن المعلومات التى يتم جمعها كانت لأغراض الإن الإفادة

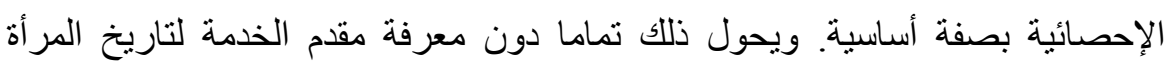

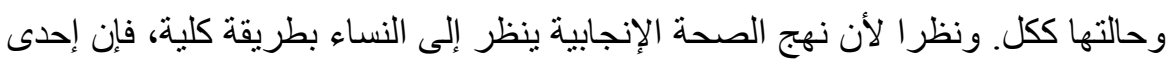

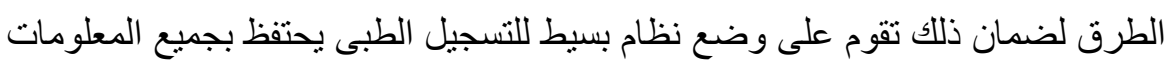
فى مكان واحد ولا يركز على الإفادة الإحصائية على حساب الصورة الإلى الإلينيكية

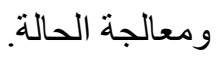


جدول 5: خذمات تنظيم الأسرة المختارة لتضمينها فى إطار العمل المقترح

\begin{tabular}{|c|c|c|c|c|c|c|c|c|}
\hline الإمدادات & التحويل & الغيدانية & المشورة & الألوية & المعدات & المظتبر & الفيصى & \\
\hline \multirow[t]{2}{*}{$\mathrm{X}$} & & & $\mathrm{X}$ & & & & & الاختيارات المتاحةة من وسائل تنظيم الأسرة \\
\hline & & & & & & & & اكتثاف وعلاج الحالات الموجودة من قبل مثل: \\
\hline \multirow[t]{2}{*}{$\mathrm{X}$} & * & & $\mathrm{X}$ & $\mathrm{X}$ & $\mathrm{X}$ & $\mathrm{X}$ & $\mathrm{X}$ & أمراض عدوى الجهاز التتاسلي \\
\hline & * & & $\mathrm{X}$ & & $\mathrm{X}$ & & $\mathrm{X}$ & سقوط الأعضاء التناسلية \\
\hline \multirow[t]{2}{*}{$\mathrm{X}$} & * & & $\mathrm{X}$ & $\mathrm{X}$ & $\mathrm{X}$ & $\mathrm{X}$ & $\mathrm{X}$ & فقر الدم (الأنيميا) \\
\hline & * & & $\mathrm{X}$ & ! & $\mathrm{X}$ & & $\mathrm{X}$ & ارتفاع ضغط الدم \\
\hline \multirow[t]{2}{*}{$\mathrm{X}$} & * & & $\mathrm{X}$ & $\varphi$ & & $\mathrm{X}$ & $\mathrm{X}$ & مرض السكرى \\
\hline & & & $\mathrm{X}$ & & $\mathrm{X}$ & $\mathrm{X}$ & $\mathrm{X}$ & البدانة \\
\hline $\mathrm{X}$ & & & & & & & $\mathrm{X}$ & مكافحة العدوى \\
\hline
\end{tabular}

* تتم الإحالة عند اللزوم، وليس فى كل حالة. 


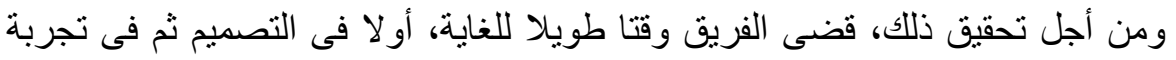
نظام تسجيل طبى مبسط. وكان الهذف هو إعداد ورقة واحدة ذات وجهين لكل امرأة، تقسم إلى أجزاء و أعمدة حسب الخدمات المختلفة (مثل رعاية الحمل، أو تنظيم الأسرة).

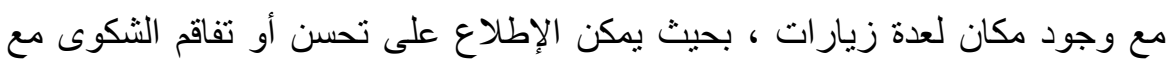

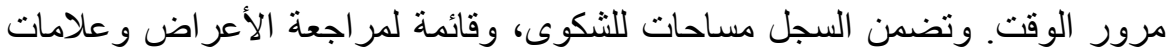

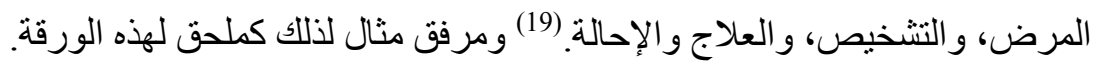

وضع معايير للرعاية

أوضحت الملاحظات الأساسية للفريق حول كيفية تقديم الخدمات أن هناك مساحة كبيرة للتحسينات فى مجالات متعددة. و على سبيل المثال، فإن التفاعل بين مقدم الخدمة و العميل

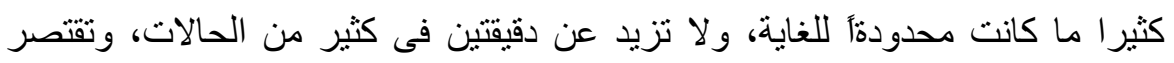

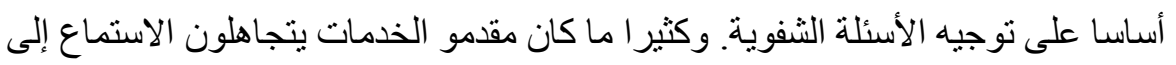

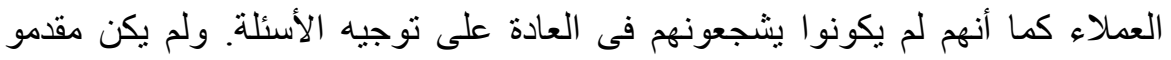

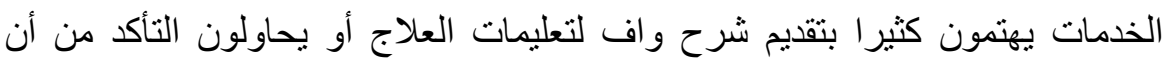
العملاء قد فهمو ها. وكان الافتقار إلى الخصوصية يمثل مشكلة أيضا. وتنطوى كل هذه

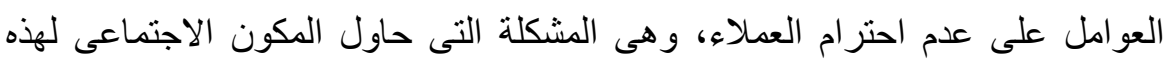

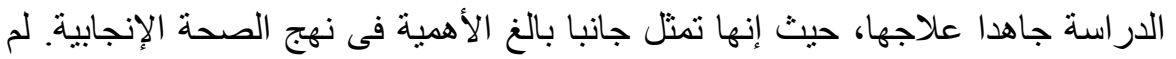

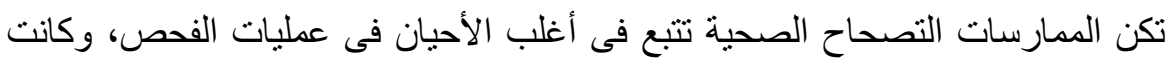

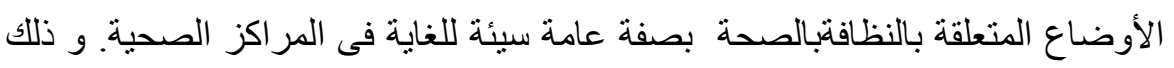

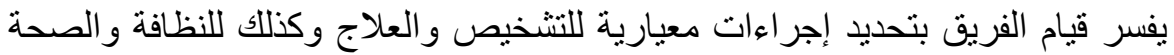

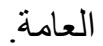

\section{تحسين التنظيم و الإدارة:}

أظهرت الملاحظات الأولية كذلك ضرورة معالجة قضايا التظظيم والإدارة. فرغم أن عدد العاملين فى كل مركز صحى لم يكن كبيرا، فإن التوصيف الدقيق للوظائف وتقسيم المسئوليات لم يكن منبعا، خاصة بين طاقم الممرضات. كانت المو اظبة على على الحضور

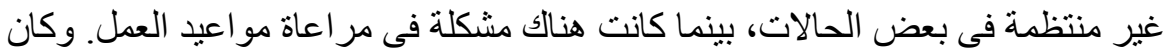

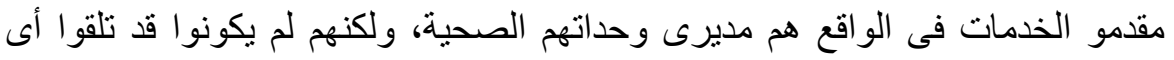
تدريبات على الإدارة قبل تعيينه.

(19) للاطلاع على مناقشة مستفيضة للسجل الطبى الذى تم وضعاه، يرجى الرجوع إلى دليل دراسة التنلل حول وسائل المر اقبة الذى أعدته جلال و آخرون. 
إن من الصعوبة بمكان تأمين ذللك، خاصة فى ظل نظام لا يحصل فيه الأطباء على الأل التدريب الكافى على الإدارة قبل تولى مسئولياتهم. و على سبيل المثال؛ كانت توريدات الأدوية للوحدة غير منتظمة، وكان ذلك يؤثر على الإقبال على الخدمات إلى حد كبير.

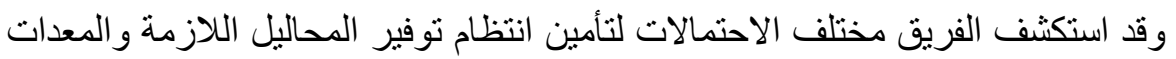
الأساسية مثل الثرائح، و القفازات ذات الاستخدام الواحد، على سبيل المثال، وهى الإنى توصيات قدمها الفريق ولم تدخل بعد فى البنية الأساسية للوز ارة. تقوية الروابط مع المستويات الأخرى:

يعتبر نظام الإحالة الفعال، ثنائى الاتجاه، إلى مستويات علاجية العاتية أعلى أمر ا ضروريا دائما

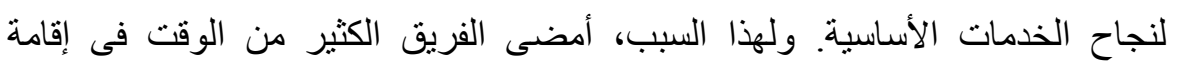

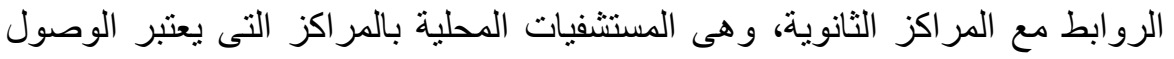

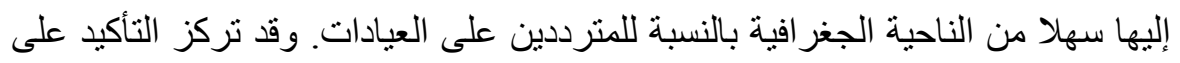
عملية استرجاع المعلومات (التغذية الاسترجاعية - الصدى الرجعى) لمقدم الرعاية

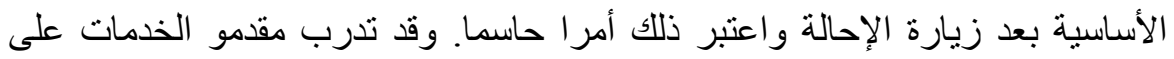
معايير الإحالة وتم تصميم وتوفير بطاقات الإحالة مع مدخلاتها.

\section{الانتقال إلى المجتمع المحلى بالخدمات الميدانية}

تدربت المرضات أيضا على كيفية نقل الخدمات الميدانية إلى المجتمع. فعقدت سلسلة

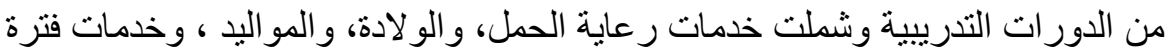

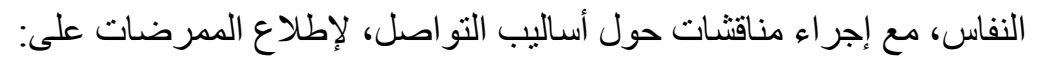
كيفية الاستعداد للزيار ات المنزلية. كيفية استخدام لغة بسيطة، وحسن المظهر الملائم، ومر اعاة حالة الأسرة.

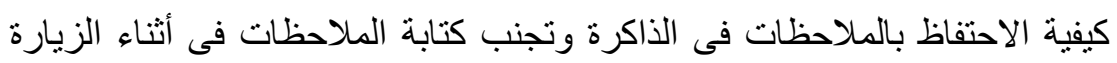
نفسـها. (20)

(20) للاطلاع على مزيد من التفصيلات، يرجى الرجوع إلى دليل دراسة التخل حول الخدمات الميدانية، إعداد

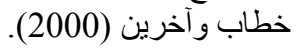




\section{2- المكون الثانى: تدريب مقدمى الخدمات ـ المبادى ع الرئيسية}

كانت هناك ثناثة مبادئ بالغة الأهمية: الأول إدراك أنه من الضرورى تدريب جميع مقدمى الخدمات العاملين فى المر اكز وليس الأطباء وحدهم؛ والثانى أن يجرى الجانب البه الأساسى من التدريب فى الموقع؛ والأخير التأكيد على النواحى الاجنماعية لتقديم الخدمات مثل التواصل وأهمية مراعاة البيئة الاجتماعية للنساء، علاوة على المسائل الفنية الأساسية. من الذى تدرب؟ يعتبر الأطباء فى هذا المستوى من الرعاية بصورة نمطية ممارسين عموميين. و عادة ما

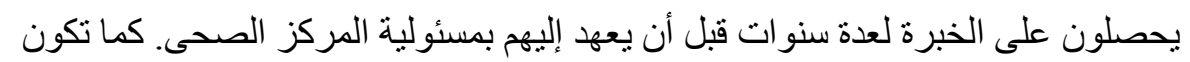
لديهم إمكانية حضور دورات تدريبية فى أثناء العمل حول تنظيم الأسرة، ومكافحة أمر اض الإسهال و علاج الجفاف عن طريق الفمالإرواء، ومعالجة أمر اض عدوى الجهاز التفسى الحادة. وقد كان لدى الأطباء الذين دربهم الفريق منوسط عشر سنوات من الخبرة على الأقل، كما أنهم حضروا جميع هذه الدورات التدريبية. وقد قام الفريق بتدريب كل من الأطباء، والممرضات، وفنيى المختبر، والمشرفين فى الموقع. كما تلقى الأطباء

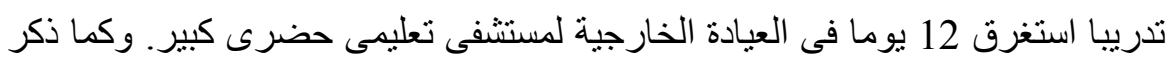
من قبل، كانت الأهداف الكلية تتمثل فى زيادة وعى مقدمى الخدمات بالصحة الإنجابية

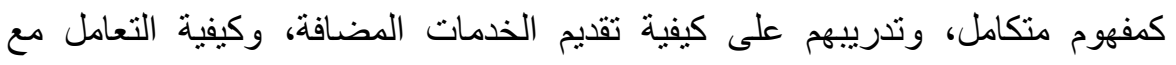
الحالات الطبية المختلفة من وجهة النظر الاجتماعية والطبية على السواء.

\section{من الأى تولى التّريب؟}

تولى التدريب الفنى لكل نوع من مقدمى الخدمات إخصائيون فى ذلك المجال نفسه. فقد قام أطباء التوليد وأمراض النساء فى الفريق بتدريب الأطباء. وقام كبار استشاريى

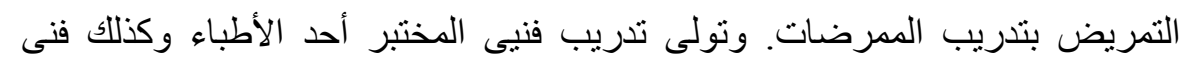
مختبر لديه خبرة عدة سنوات. وقام علماء الاجتماع من أعضاء الفريق بتدريب جميع لثابع مقدمى الخدمات على النواحى الاجتماعية التى ينبغى أن يأخذوها فى الحسبان عند تقديم 
ما الذى تناوله تلدريب مقدمى الخدمات؟ أ ( أهمية السياق الاجتماعىى:

بالنسبة لجميع مقدمى الخدمات، أكد المنهج التدريبى على أهمية الاستماع إلى النساء

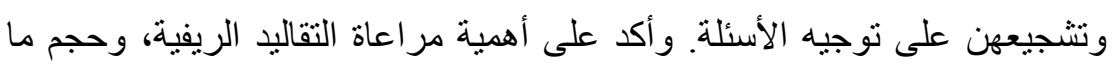

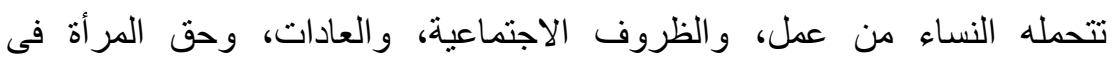
الخصوصية والمشورة. كما أوضح التدريب الاجتماعى لمقدمى الخدمات مفاهيم النساء عن الصحة و الخدمات الصحية.

ب) النواحى القنية في عملهم:

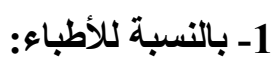

تتخيص، وعلاج، ومتابعة حالات أمر اض النساء البسيطة التى يمكن معالجتها على مستوى الرعاية الأساسية.

معالجة منابعة حالات رعاية الحمل، و التأكيد على التشخيص المبكر لعو امل

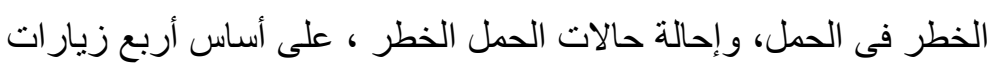
لر عاية الحمل كحد أدنى لكل حالة. تقديم المشورة لتنظيم الأسرة ومكافحة العدوى. معايير التحويل ملء الملفات الطبية واسترجاعها المشورة و التو اصل

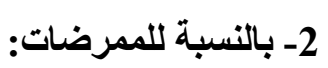

التدريب الفنى على دور الممرضات فى رعاية الحمل، وتنظيم الأسرة، ونوفير خدمات أمر اض النساء. الحفاظ على الصحة بصفة عامة و التعقيم بصفة خاصة كيفية الاحتفاظ بالملفات وتسجيل تاريخ كل حالة كيفية القيام بزيار ات ميدانية كيفية توجيه رسائل التثقيف الصحي

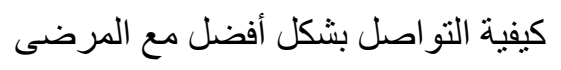
3- بالنسبة لفنيى المختبر: 
حيث إن كل مركز صحى فى مصر به مختبر أساسى، وفنى مختبر، فقد

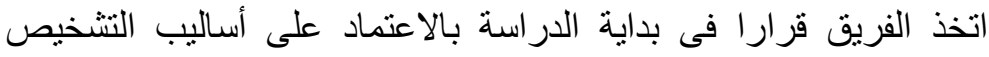
المعملى الفعلى لتحديد أمراض عدوى الجهاز التناسلى بدلا من المعالجة على أساس الأعراض.(21) وقد كان الهدف من تدريب الفنيين هو تمكينهم

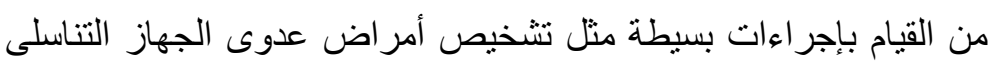

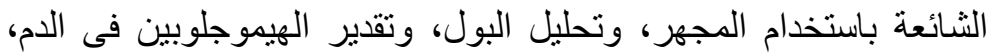
وقياس مستويات مستوي السكر، وإجر اء اختبارات الحمل وتحديد فصيلة الدم من نوع ريسس. ولمشاركة الفنيين فائدة مضافة حيث إنها تخفق عبء إكباء القيام بهذه العمليات عن الأطباء.

وقد أعقب التدريب المبئيى عقد دورات تنثيطية فى الموقع، مرتين أسبوعيا،

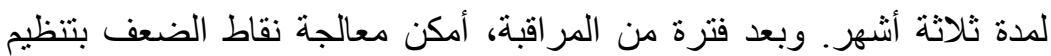
دورة إضافية شملت زيارتين أسبو عيا لمدة شهرين آخرين.

3- المكون الثالث: الارتقاء بالبنية التحتية المادية وتوفير المعدات

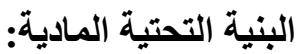

كانت المر اكز الصحية فى حاجة ماسة إلى إصلاحات مادية أساسية. وحرص الفريق

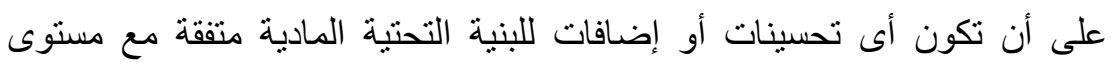
الرعاية الأساسية للعيادات. وكان من الأمور المهمة للغاية أن تكون تكلفة التغييرات

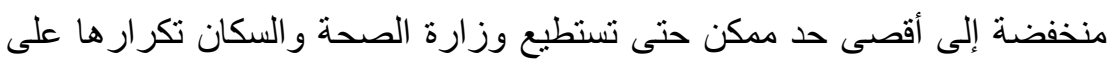

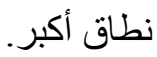

وقد تضمنت التحسينات المادية أعمالا مثل دهان حجرات الفحص ، و التأكد من

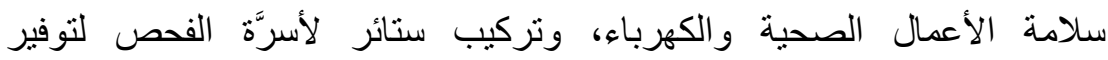
الخصوصية، وتركيب سلك للنو افذ لمنع الذباب والبعوض. كما تمت تنطية السطح العمل بالمختبرات بالبلاط. وقد أسهم المجتمع فى صورة تبر عات فردية فى تغطية

$$
\text { نفقات الجانب الأكبر من التحسينات المادية. }
$$

(21) لمناقثة الحجج المؤيدة و المعارضة للمعالجة على أساس الأعر اض بالنسبة لأمر اض عدوى الجهاز التناسلى، يرجى الرجوع إلى ممدانى (1999). 
تعتبر نوعية المعدات المطلوبة لتوفير الخدمات الوارد ذكر ها فى إطار در اسة الفريق أساسية تماما، وهى موجودة بصورة عادية فى غالبية عيادات المستوى الأول، وتكمن المشكلة عادة فى الصيانة وليس فى شراء الأجهزة الغالية. وقد قام الفريق بفحص واختبار جميع المعدات مثل أجهزة التعقيم، والمجاهر ، و المناظير. وتم تغيير عدسات المجاهر الضوئية بأخرى جديدة كانت فى المخازن، وتم توفير الثرائح الزجاجية وأغطيتها. وتولت وزارة الصحة والسكان توفير الجانب الأكبر من بن احتياجات المعدات المطلوبة للمر اكز الصحية الثناثة، وذللك من مخازنها، وتم شر اء وله القدر القليل المتبقى من ميز انية الدراسة. وقد وفرت الدراسة أساسا" أجهزة التعقيم

$$
\text { و أدو ات التنظيف. }
$$

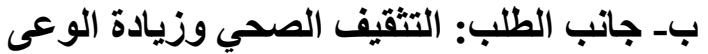 هل تدرك النساء شروط الصحة للوضع الرابل الهن للصحة الإنجابية؟}

كانت أعمال الفريق السابقة قد أوضحت أن النساء لا يعانين فقط من مستوى مرتفع غير

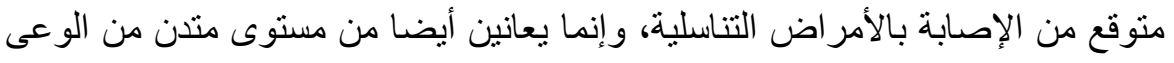

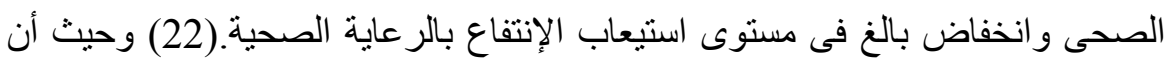

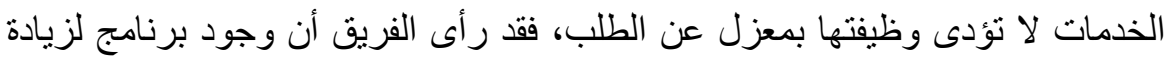

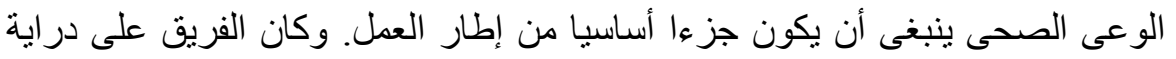
تامة بالقيود الاجتماعية، والثقافية، و الاقتصادية فى حياة النساء و التى نؤثر فى قدرنهن

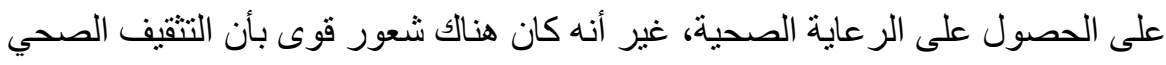
سيزود النساء بالمعلومات مما سيمكنهن من اتخاذ القرارات. وتم تدريب المثقفين

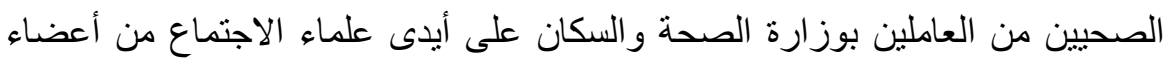
الفريق، وذللك باستخدام منهج المشاركة.(23) 


\section{ما الذى استهـف تحقيقه برنامج التثقيف الصحي؟}

زيادة وعى النساء والرجال بشأن صحتهم بصفة عامة وبالصحة الإنجابية بصفة خاصة. تمكين النساء بتزويدهن بالمعلومات لاتخاذ القرارات الخاصة بصحتهن.

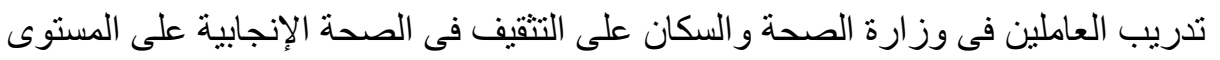
المجتمعى ، كجز من عملية نقل إطار العمل وكنللك تثجيع الاستدامة.

وقد أعدت سلسلة من الرسائل الصحية المحددة القصبرة بلغة محلية سلسة ملائمة؛ وقامت بتطبيقها فى الميدان إخصائية الأنثروبولوجيا وفريقها الميدانى من أجل: مساعدة النساء فى إعادة ترتيب أولوياتهن بشأن صحتهن بصفة عامة. مساعدة النساء على التعرف على أعر اض الأمر اض التناسلية. تشجيع النساء على التماس المشورة الطبية كلما استلزم الأمر ذلك. المساعدة على تمكين النساء من اتخاذ قرار اتهن الخاصة بشأن صحتهن. تثجيع النساء على تكوين نظام تثبيك فعال. تعزيز الثقة لاى النساء بأن مساهنتهن فى البيت وفى المجتمع ضرورية وجديرة بالاهتمام وتستحق التقدير.

كذلك تم إعداد رسائل مناسبة للرجال، ولصانعى السياسة، ومقدمى الخدمات. 
1- كانت المهمة الأولى للفريق إجراء مسح قاعدى الأساسى للوضع فى ل عزيران/

يونية 1996

إلى شباط/

فبرير 1997

حزيران/

يونية 1996

إلى شباط/

فبرير 1997

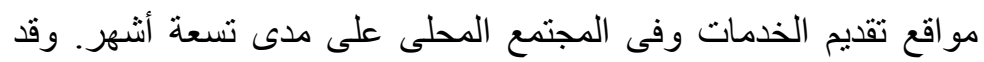
أوضح ذلك كيفية تقديم الخدمات فى المراكز الصحية، وكان أمرا

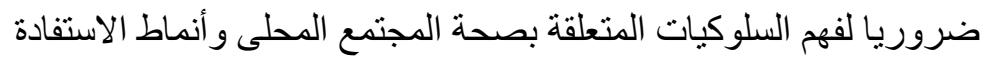
بالر عاية الصحية. وكان الفريق حريصا على جمع البيانات النوعية الكيفية

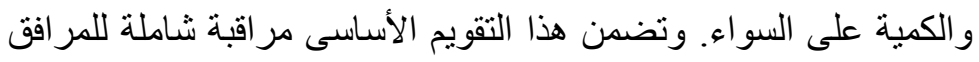
لعملية تقديم الخدمات فعليا" ؛ ومراقبة المقابلات (بين العميل ومقدم الخداء

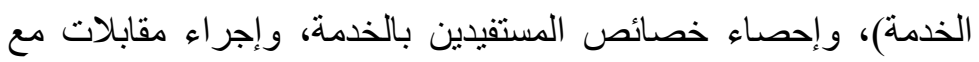
مقدمى الخدمات، ومسح لرضاء العملاء عن الخدمة، ودر اسة تكلفة تقديم الخدمة لكل مستفبد بالنسبة لوزارة الصحة. وتم أيضا استكثاف البيئة المادية والاحتياجات المطلوبة لتحسينها. وتضمن جمع البيانات المجتمعية إجر اء مسح أسرى للأسر المعيشية مع النساء لتوثيق النطاق الاجتماعى ولئي

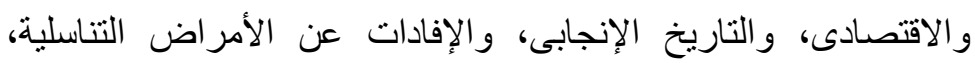

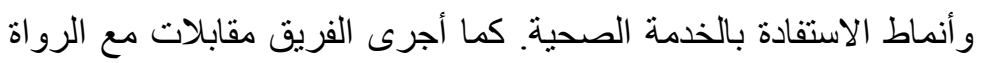

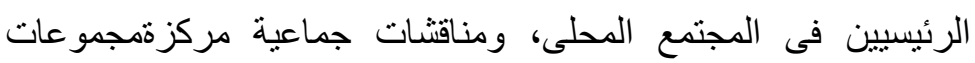
بؤرياه. عمل الفريق، فى الوقت نفسه، على اختيار المناسب من مكونات الخدمات لتضمينه فى إطار الصحة الإنجابية فى هذا المستوى من الرعاية الصحية. و استغرق ذللك عدة أثنهر من الفحص لقضايا عديدة شملت:

أ) احتياجات الصحة الإنجابية الموثقة على مستوى المجتمع المحلى.

$$
\text { ب) الخدمات الفعلية التى يجرى تقديمها. }
$$

ج) الثغرات الموجودة بين الاحتباجات و الخدمات: تحديد العناصر التى يمكن إضافتها إلى مجموع الخدمات على المستوى الأساسى الاهي و الثكل الذى ينبخى تقديمها فيه.

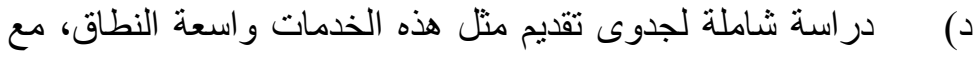
الأخذ فى الحسبان مدى القبول، واحتياجات التدريب، و التكاليف،

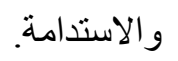

ه) التدريب المطلوب لمختلف أنواع مقدمى الخدمات. و) تصميم التحسينات الأساسية للبيئة المادية بتكلفة منخفضة. 


\begin{tabular}{|c|c|c|}
\hline & 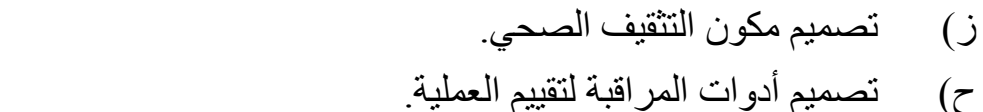 & \\
\hline & التطبيق الميدانى & -3 \\
\hline آيار / مايو & جرى التطبيق الفعلى لمختلف المكونات فى المبدان فى شتاء 1997 وربيع & \\
\hline 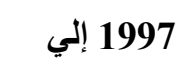 & وأو ائل صيف 1998. وتم البدء فى برنامج التثقيف الصحي وتنفيذه لفترة & \\
\hline 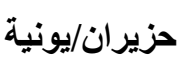 & استمرت سبعة أثهر،(24) بعد اختبار مسبق للوعى الصحى فى المجتمع & \\
\hline 1998 & المحلى. وجرى تدريب مختلف أنواع مقدمى الخدمات خلال هذه الفترة. (25 & \\
\hline & ) واستكملت عملية التحسينات منخفضة التكاليف للبيئة المادية(26) وبدأت & \\
\hline & مشاركة المجتمع المحلى فى العملية. & \\
\hline 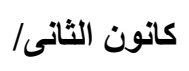 & المراقبة وإعادة التدريب: فى كانون الثانى/ يناير 1998، بدأ الفريق فى & -4 \\
\hline يناير 1998 & مراقبة أداء المكونات المختلفة فى الميدان، مستخدما وسائل المراقبة & \\
\hline إلى آيار/ مايو & وقو ائم المر اجعة المصممة خصيصا لذلك. و استغرقت هذه المرحلة خمسة & \\
\hline 1998 & أثهر. وبعد تحليل البيانات، أعيد التدريب لمدة شهرين بالمر اكز الصحية & \\
\hline & ل لمعالجة المشكلات التى تم تحديدها. & \\
\hline 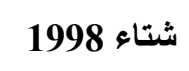 & التقيبم والتحليل & -5 \\
\hline 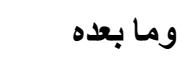 & تم إجر اء التقييم النهائى لأداء مكونات التدخل المختلفة فى شتاء 1998- & \\
\hline & 1999 على مدى ستة أشهر. ثم بدأ الفريق فى تحليل ونشر النتائج، وهذا & \\
\hline & ما زال جاريا حتى كتابة هذا التقريز. ويوجرى إصدار الأدلة الخاصة بكل & \\
\hline & مكون من مكونات إطار العمل، حتى يستطيع الآخرون محاكاة التجربة، & \\
\hline & وذللك بالإضافة إلى إصدار سلسلة السياسات التى تتناول بالتفصيل مختلف & \\
\hline & & \\
\hline
\end{tabular}

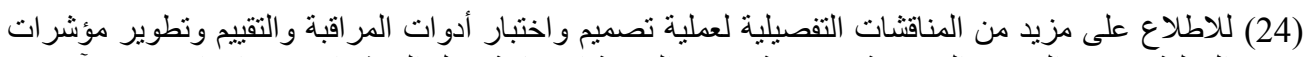

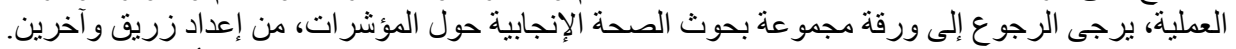

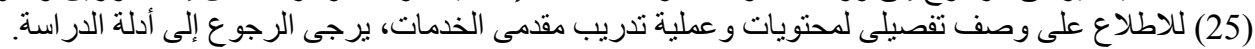
(26) للاطلاع على وصف تفصيلى لعمليات التحسين، يرجى الرجوع إلى دليل الارتقاء بوحلى الثرات الرعاية الأساسية الرية 


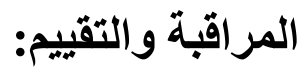

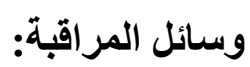

بعد أن انتهت عمليات التحسين المادية ووضعت المعدات فى أماكنها، وتم تدريب مقدمى الخدمات،

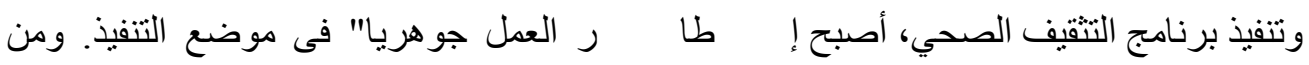

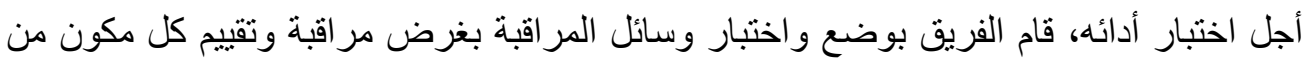

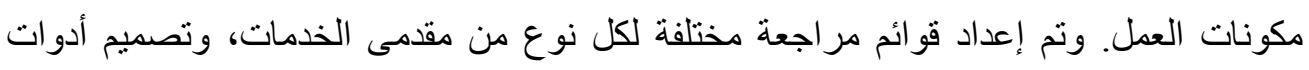

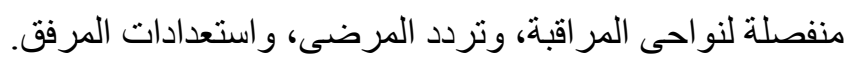

\section{كيف جرث المراقبة؟}

بدأ الفريق بعد ذلك فى مر اقبة تقديم الخدمات وخصائص مستخدمى المر اكز الصحية، من خلال

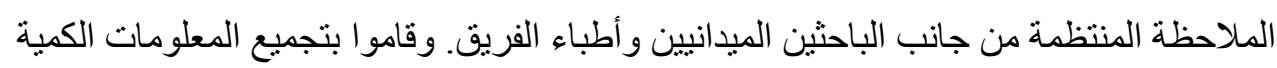
و النوعيةو الكيفية، مستخدمين قو ائم المر اجعة التى تم إعدادها لأغر اضل الثن الملاحظة.

وقد تم تقييم برنامج التثقيف الصحي بإجر اء اختبار قبلى وآخر بعدى للوعى الصحى، بالإضافة إلى الحصول على الصدى الرجعى من الددربين فى أثناء عملية التدريب بالمشاركة.

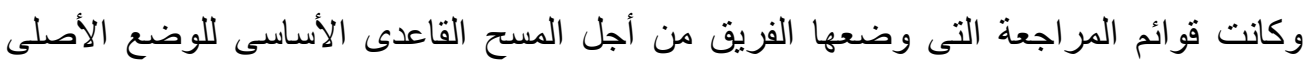

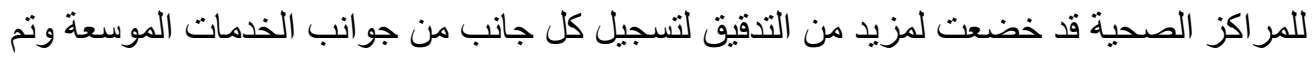

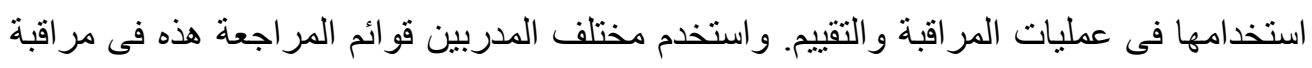

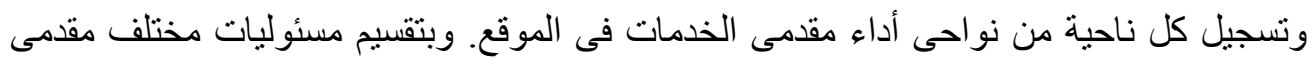

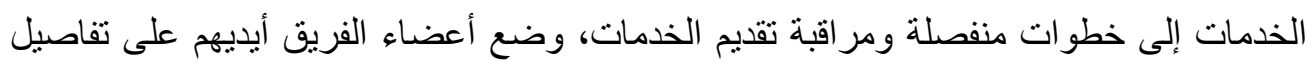

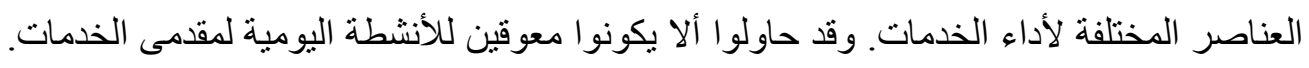

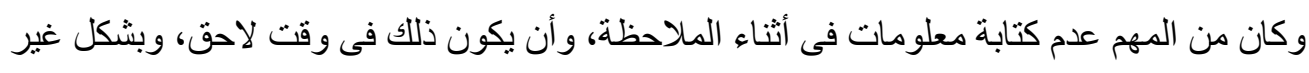
ملفت. وقد ذكر لمقدمى الخدمات أن الغرض من هذه الملاحظات هو المساعدة فى تحديد المشكلات

$$
\text { و المساعدة فى حلها. }
$$

وقد تتاوب القائمون بالملاحظة العمل بين المراكز الصحية وكانوا حريصين على عدم التنخل فى دئ

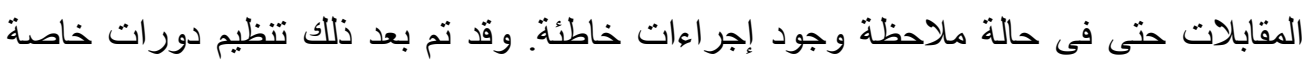

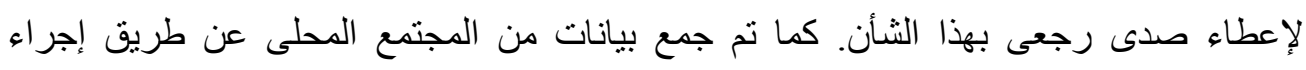

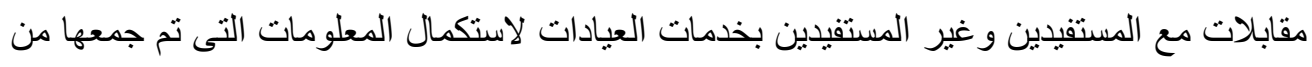

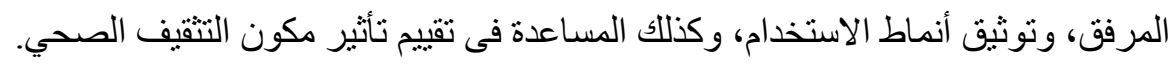


ويوضح الجدول 6 الوسائل المختلفة التى وضعها الفريق للمر اقبة والتقييم. وقد تم اختيار مؤشر ات العملية ويجرى وصفها بالتفصيل، مع الوسائل نفسها, فى إصدار ر قادم.اخر.

جدول 6: وسائل المراقبة المستخدمة فى المراحل المختلفة

\begin{tabular}{|c|c|c|c|}
\hline التقييم & المر اقبة & القاعدى الأسـاسى & \\
\hline$\sqrt{ }$ & & $\begin{array}{l}\sqrt{ } \\
\sqrt{ } \\
\sqrt{ } \\
\sqrt{ }\end{array}$ & 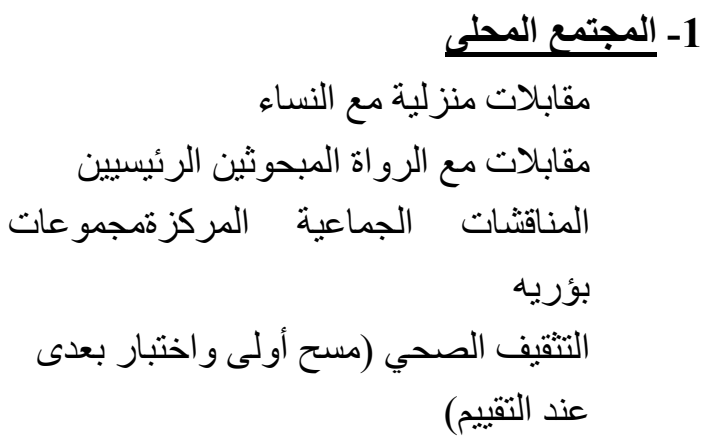 \\
\hline $\begin{array}{l}\sqrt{ } \\
\sqrt{ }\end{array}$ & $\begin{array}{c}\sqrt{ } \\
\sqrt{ } \\
(29) \\
(30)\end{array}$ & $\begin{array}{l}\sqrt{ } \\
(27) \\
(28) \\
\sqrt{ } \\
\sqrt{ } \\
\sqrt{ } \\
(31)\end{array}$ & 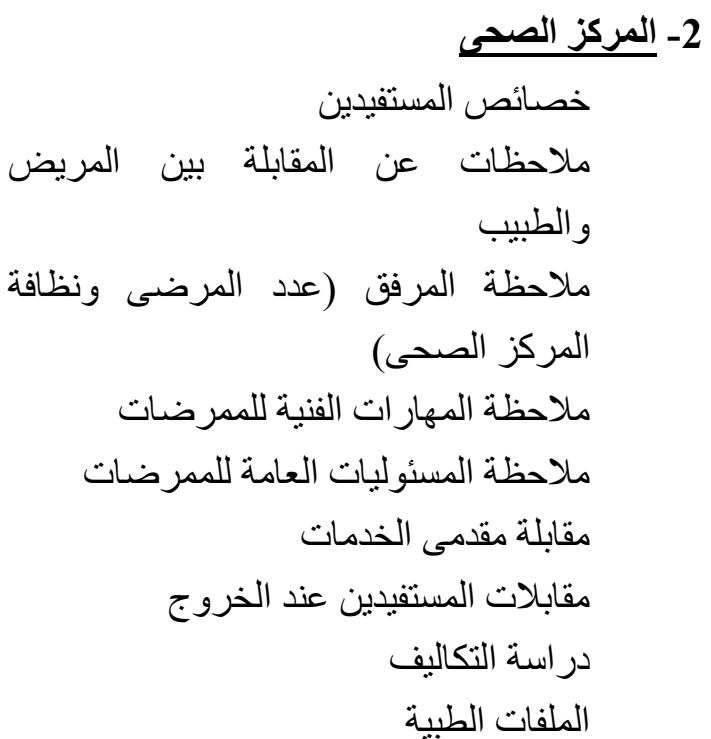 \\
\hline
\end{tabular}

(27) لوحظت المهار ات الفنية للممرضات فى أثناء المرحلة القاعدية، ولكن بدون استخدام قائمة مر اجعة تفصيلية.

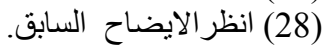

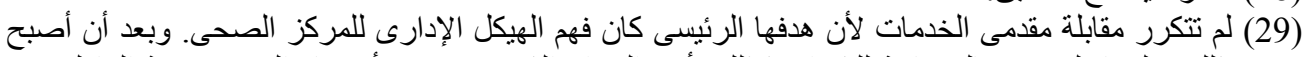

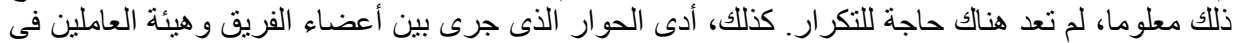

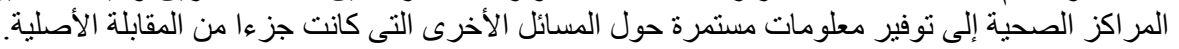

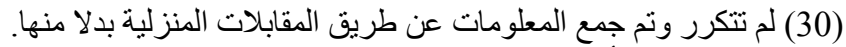

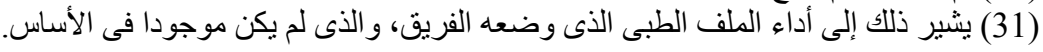




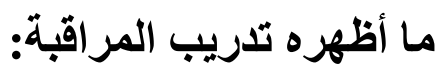

بينما أظهرت عملية المر اقبة تحسنا عاما، فإنها حددت أيضا المجالات التى تحتاج إلى مزيد من التهن

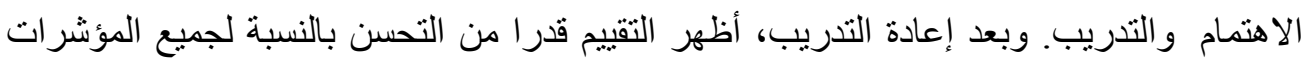

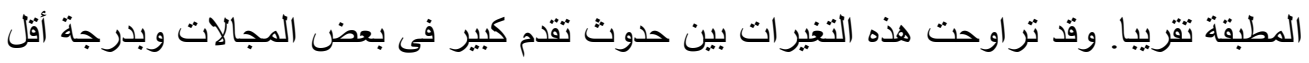

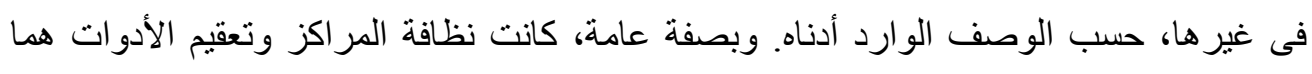

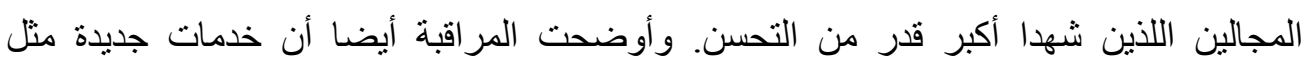

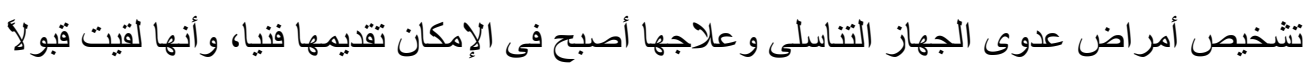

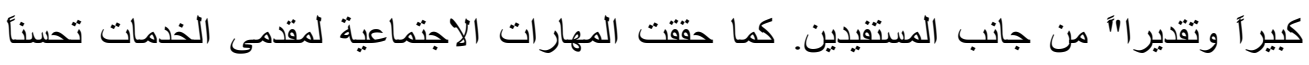
ملحوظأ. وظلت بعض المسائل تمثل مشكلات كما سيجرى شرحه أدناه.

التقييم: الجدوى وليس الأثر

صعوبة إسناد الأثر:

رأى الفريق منذ بداية الدراسة ألا يحاول توثيق الأثر المحتمل لإطار الخدمات على الوضع الإنع

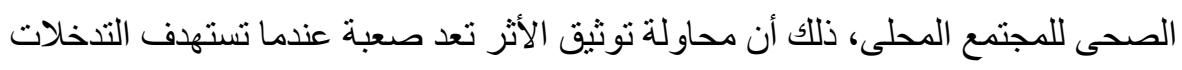

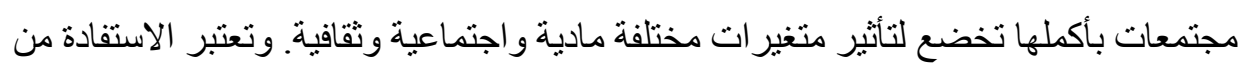

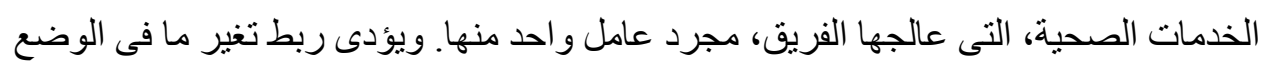

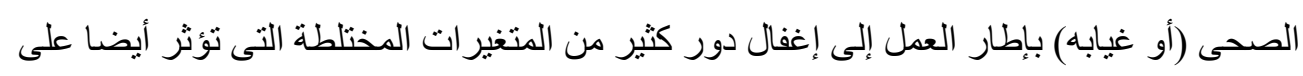

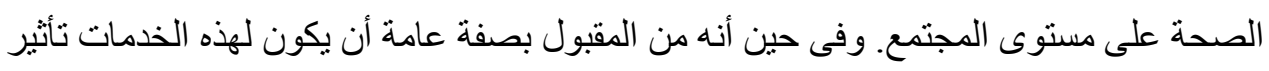

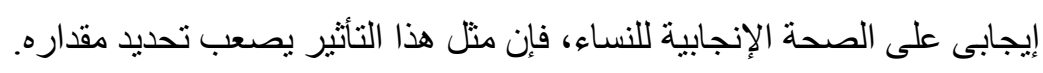

\section{توثيق العملية والنتائجعملية التوثيق ونتائجها:}

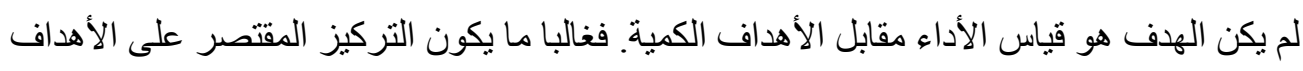

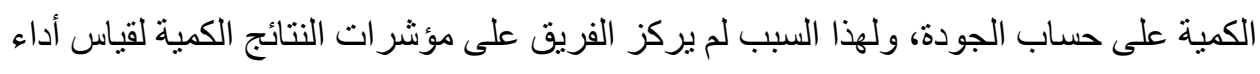
الككونات المختلفة. وبدلا من ذللك، ركز الفريق على مؤشر ات العزات العملية (التى تسمى أحيانا

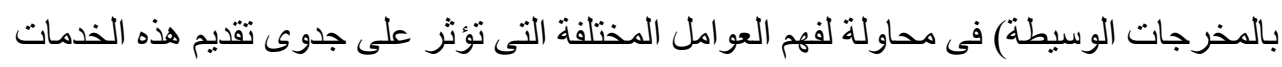
في عيادات الرعاية الأساسية. 


\section{ونورد فيما يلى التغيرات المهمة والاروس المستفادة:}

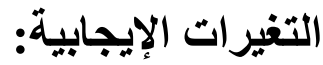

1- زيادة الطلب على خدمات الصحة الإنجابية: نزايدت نسبة النساء المترددات على خدمات

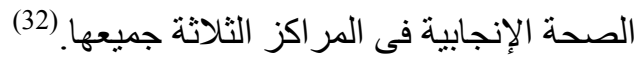

2- تقدير النساء للخدمات الجديدة: على سبيل المثال أن المستفيدات تعودن على وجود خدمات التحليل المعملى وعلاج أمراض عدى عدى الجهاز التناسلى فى الموقع، وأبدين

اهتمامهن بالحصول على هذه الخدمات وبدأن بطلبنها.

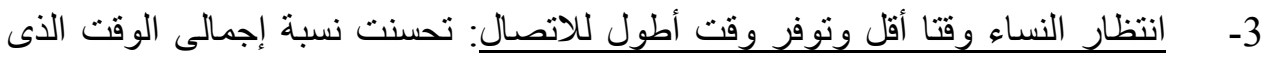

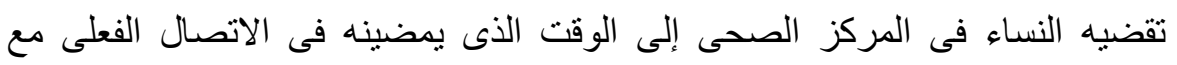

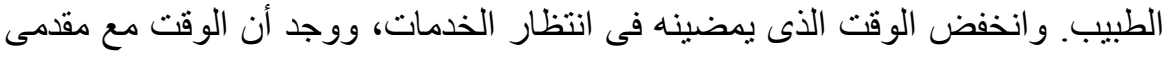
الخدمات قد تضاعف تقريبا" عما كان عليه فى الأساس.

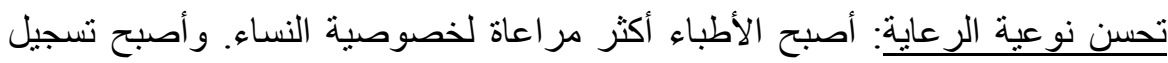

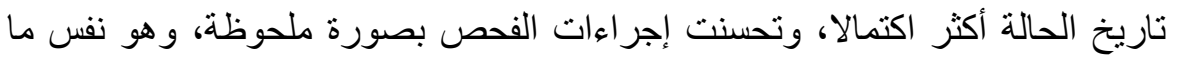
حدث بالنسبة للتشخيص الملائم وتبادل المعلومات في أثناء المقابلة. شعر مقدمو الخدمات بقيمة الاحتفاظ بالملفات الفردية للعملاء، حيث أصبحوا يقدرون قيمتها فى متابعة تاريخ حالة المر أة عبر الوقته

6- تحسن أداء الممرضات: أصبحت الممرضات يقمن أكثر بمساعدة الأطباء كما أصبحن أثد حماسا لوظائفهن بصورة ملحوظة.

تحسن مكافحة العدوى: وجد أن إجر اءات تعقيم الأدوات بصفة خاصة قد تحسنت بدرجة كبيرة وثابتة.

تدرب فنيو المختبر على تحديد أمر اض عدوى الجهاز التناسلي: بعتبر التشخيص البسيط

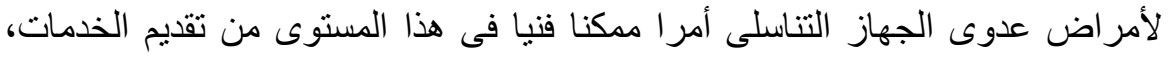
بشرط إعطاء الفنبين التدريب الأساسى اللازم. كانت عمليات التشخيص المعملى فى الموقع مفيدة: أدى قيام فني المختبر بتقديم المساعدة

فى تنخيص حالات أمر اض عدوى الجهاز التناسلى المختلفة إلى تحسين نوعية الرعاية الرعاية

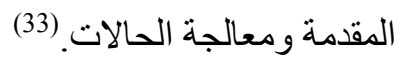
10- أصبحت المر اكز أكثر نظافة: بدت حالة المر اكز الثلاثة من ناحية المو اصفات الصحية

(32) بالرغم من أن هذه الزيادة انخفضت إلى حد ما فى مرحلة التقييم، فقد فسر ذلك بتو افقها مع دخول المدارس

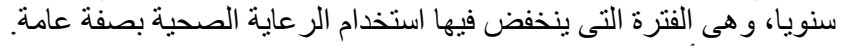

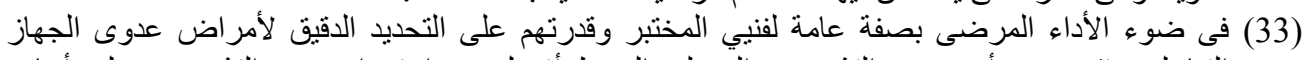

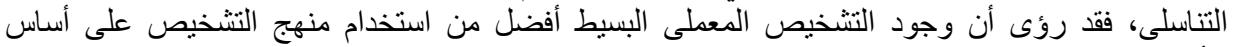
الأعر اض الذى ينسم بصفة عامة بضعف قيمته التنبؤية. 
بصفة عامة أفضل بصورة ملحوظة.

11- كان برنامج التقيف الصحي مؤثرا: أثرــالتقيف الصحي بسر عة فائقة على طلب خدمات

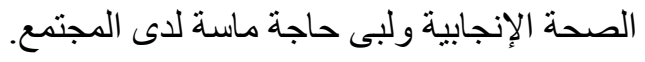

\section{ما الذى تعلمناه؟}

إن إطار ا بسيطا من خدمات الصحة الإنجابية الأساسية يمكن نوفيره على مستوى الرعاية

الأساسية.

إن هذه الخدمات ينبغى أن تتضمن علاج حالات أمراض النساء البسيطة، وتنظيم الأسرة، ور عاية الحمل وفترة النفاس.

إن هنالك حاجة كبيرة لهذه الخدمات و هى تحظى بتقدير المستفيدين. إن الأطباء الذين يقدمون هذه الخدمات لا يشترط أن يكونوا إخصائيين.

إن الأطباء يمكنهم أن يتعلموا إجراءات جديدة حتى وإن كانوا معتادين على تقديم نفس

الخدمات لسنوات.

إن الممرضات يمكنهن التجاوب كثير ا مع الخدمات الجديدة وأن يتحمسن للمشاركة. إن بإمكان الفنبين العاملين فى المر اكز أن بتعلموا و أن يقوموا بأنشطة معملية بسيطة بالنسبة لحالات الصحة الإنجابية.

إن المراكز ليست فى حاجة إلى الكثير من المعدات الجديدة لكى تقدم خدمات الصحة الإنجابية.

إن المعدات المطلوبة ليست مرتفعة التكلفة أو معقدة.

إن التحسينات المادية المطلوبة لتقديم هذه الخدمات أساسية وليست عالية التكلفة.

إن استخدام ملف مصمح بعناية، ومتكامل ، وبه مساحات لتسجيل الزيار ات اللاحقة، يعطى

لمقدمى الخدمات خلفية عن التاريخ الطبى للعميل، مما يؤدى إلى تقديم رعاية أفضل جودة. إن السجلات الطبية المصممة لجمع الإحصاءات بدلا من التركيز على الصورة الإكلينيكية للفرد لا تساعد المسئولين فى العيادات فى معالجة الحالات. إن تزايد استخدام المر اكز يعنى زيادة دخل مقدمى الخدمات.

إن نزايد الإقبال يمكن التغلب عليه إلى حد كبير بتحسين المهارات الإدارية والعمل الجماعى.

إن هناك اهتماما بالغا بين مقدمى الخدمات والمشرفين بالحصول على التدريب فى مجال 


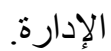

إن توافر الأدوية مجانا أو بصورة مدعمة يمثل عاملا مهما فى إقدام النساء على اتخاذ

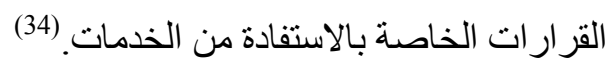
إن إثراك مقدمى الخدمات فى اتخاذ القرارات أمر مهم، وينبخى أن بتمتعوا بمزيد من الاستقلال الذاتى الإدارى.

إن الثقافة الصحية التى تتوافر تقدم بعناية تؤدى بالفعل إلى رفع الوعى الصحى وتزود النساء بالمعلومات التى تمكنهن من اتخاذ القر ار ات بشأن صحتهن. إن المثقفين الصحيين بوزارة الصحة و السكان الذين اعتادوا تقديم الرسائل عن تتظيم الأسرة

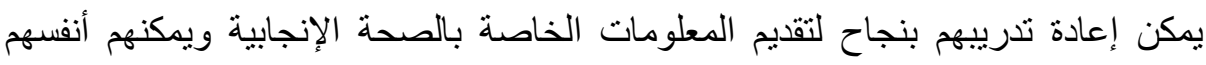
العمل كمدربين.

\section{التحديـات}

لم يخل تصميم وتتفيذ إطار الصحة الإنجابية من بعض التحديات من ناحية المفاهيم والإمدادات، منها:

أولا - تصميم الإطار: كان يمثل تحديا من ناحية المفهوم، نظر الأنه كان يعنى الاختيار ، من

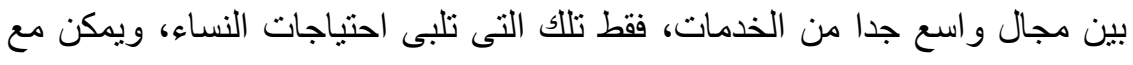
ذللك تقديمها فى المستوى الأساسى. وقد أخذت فى الاعتبار عوامل كثيرة من أجل الوصول إلى المكونات الموضحة عاليه.

\section{ثانيا - مسائل الإمدادات الأكثر تحديا تضمنت ما يلى: \\ مسائل إدارة المركز الصحي:

يعد الأطباء العاملون فى هذه المر اكز الصحية أكثر من مجرد مقدمى خدمات. فهم أيضا

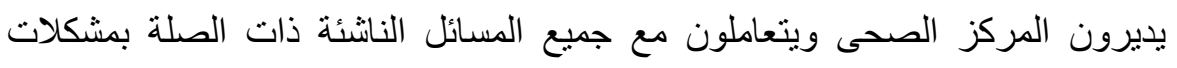

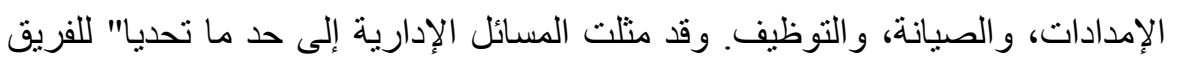

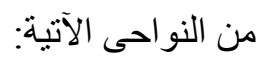

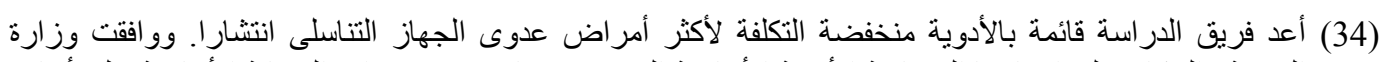

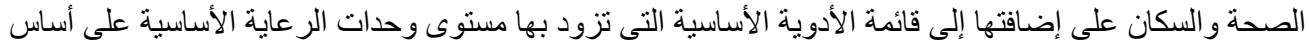
قو مى. ويتو قف تقديمها حاليا على الميز انية المتاحة. 
كان تأمين استمرار الإمدادات يمثل مشكلة. إذ لم تكن الإمدادات المطلوبة

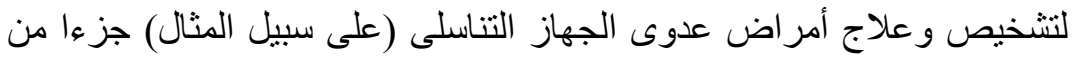
نظام وزارة الصحة والسكان. واستكثف الفريق الاحتمالات المختلفة لتأمين الإني

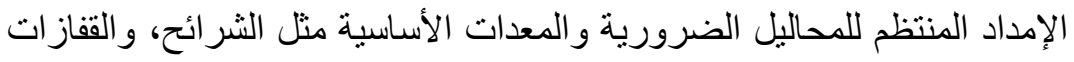

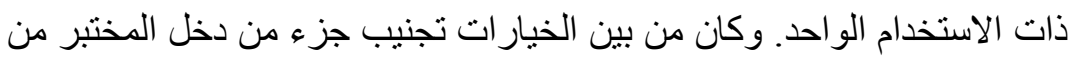

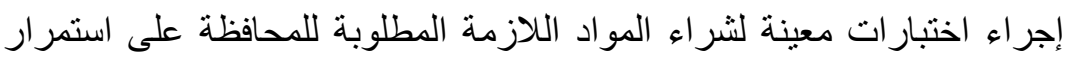

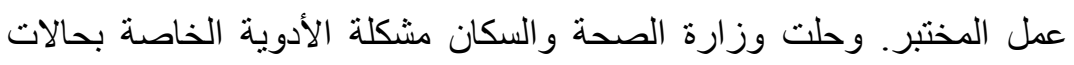
الصحة الإنجابية بأن عرضت دمج قائمة الأدوية التى اقترحها الفريق فى قائمتها الدو ائية الأساسية. (بيد أن توريد هذه الأدوية كان غير منتظم إلى حد مان).

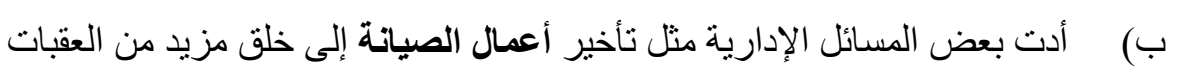

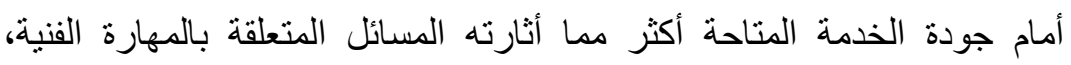
و انسحب ذلك على كل مستويات مقدمى الخدمات. (و على سبيل المثال: كان جهاز

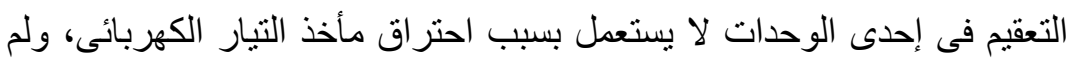

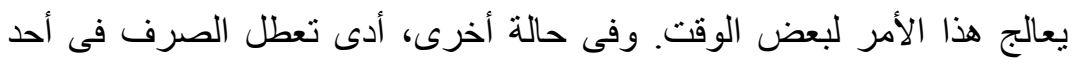

$$
\text { المختبر ات إلى توقف خدمات المختبر لبعض الوضى لوفت). }
$$

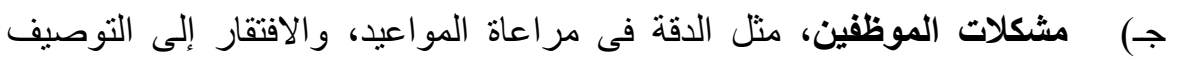

$$
\text { الوظيفى، و الملابس الملائمة، كانت تنتشأ أحيانا. }
$$

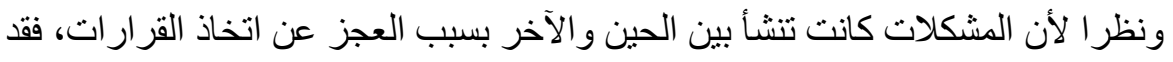
شعر الفريق بأن الأطباء سيستفيدون كثيرا من تنظيم دورة تدريبية قصيرة لهم فى الإنى الإدارة. وقد لقى ذلك اهتماما بالغا.

$$
\text { التندريب: }
$$

بينما كان تدريب مقدمى الخدمات ناجحا فى حالات كثيرة، فإن ذلك لم يكن الحال دائما.

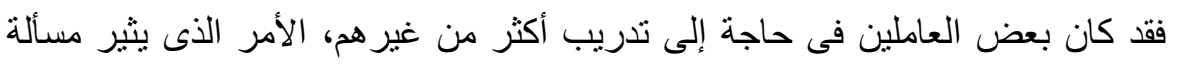

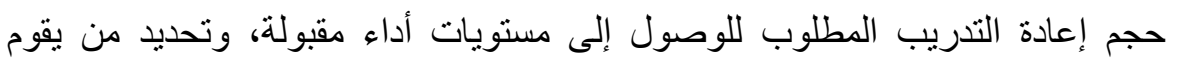
بالتدريب و التكاليف المرتبطة بذلك.

$$
\text { التأكد من الأداء الملائم لنظام التحويل }
$$

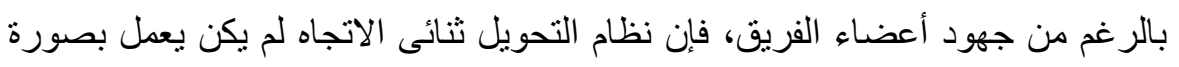

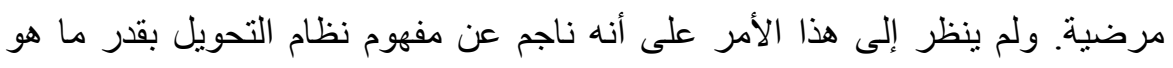

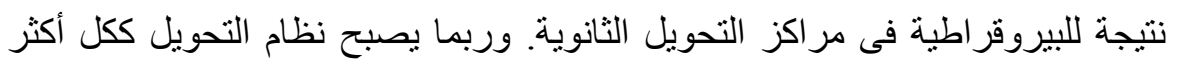

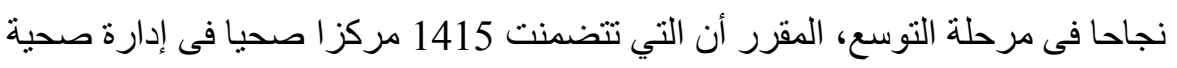


واحدة، تتبع مستشفيين اثنين.

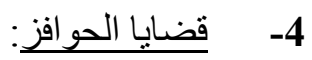

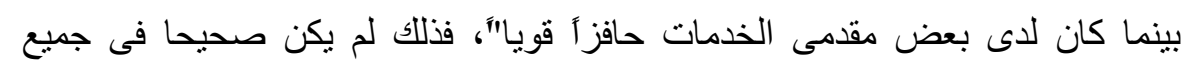

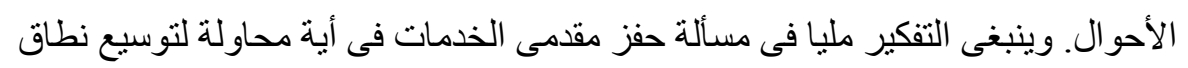

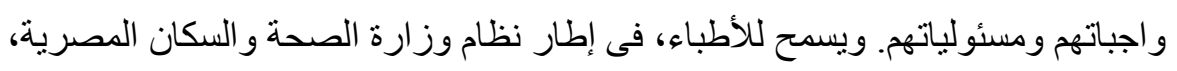

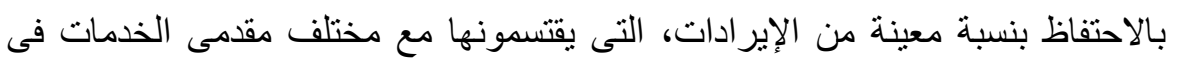

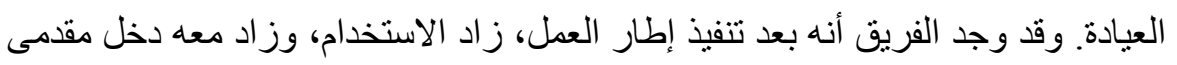
الخدمات. وقد ثبت أن ذلك يمثل حافز ا جيدا.

مسائل الإشر اف

لكى يكون أداء إطار العمل مرضيا؛ يستلزم الأمر إثر افا صارما على مستوى الإدارة

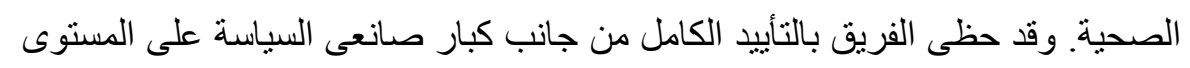
المركزى ومستوى المحافظة. بيد أن معدل تغيير الموظفين على مستوى الإدارة الصحية الصانية كان عاليا. ومن المنظظر أن يصبح مشرفو الإدارة أكثر مشاركة في مرحلة التوسع.

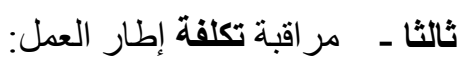

كانت إحدى المسائل التى اهتم بها الفريق مسألة تكلفة إطار العمل بالنسبة للخدمات،

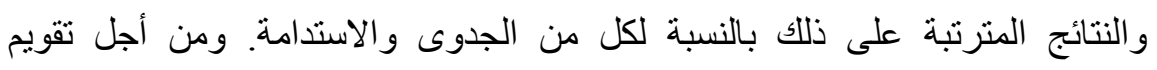

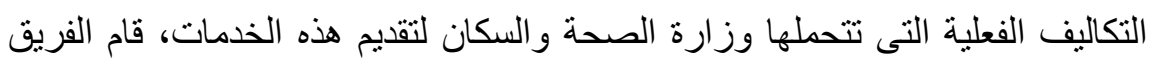

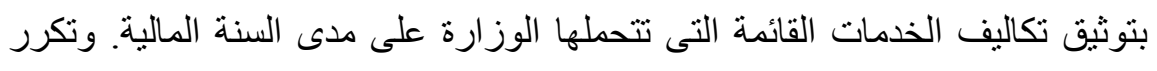

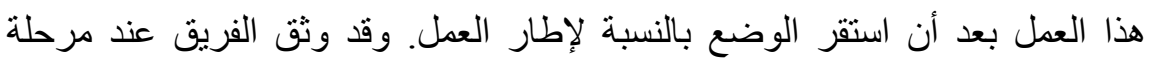

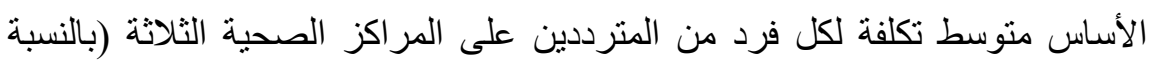

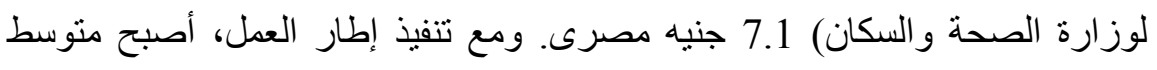

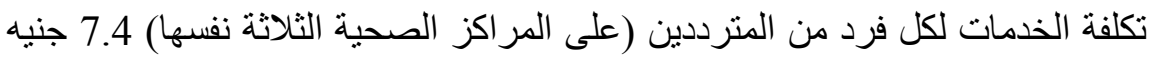

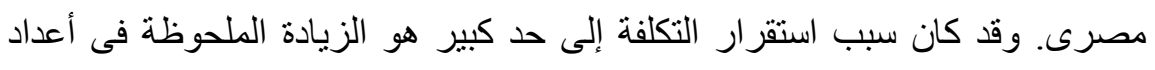

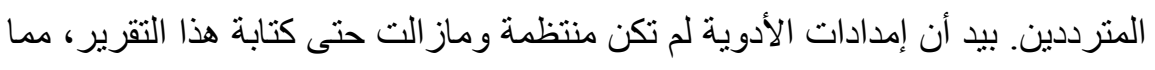

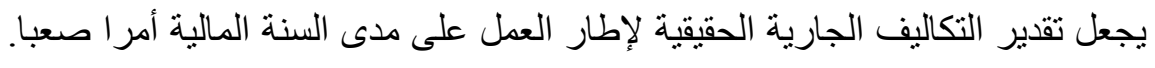

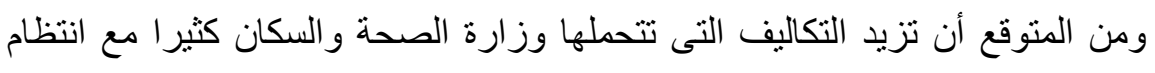
إمدادات الأدوية وسد النقص الذى تحتاجه خدمات الصحة الإنجابية. وتثير هذه الثقدير ات، كما سبقت الإثارة إليه، إلى ما يحمله تثغيل إطار هذه الخدمات

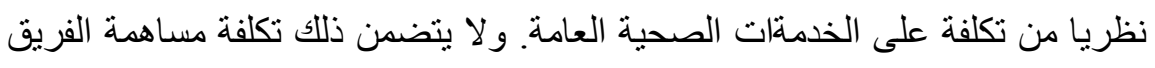
فى وضع إطار العمل. كما أنه لا يتضمن تكاليف مكون التنقيف الصحي أو ما سيتكلفه 
تنفيذ برنامج تدريبى شامل.

\section{مضامين السياسة دلالات على السياسات}

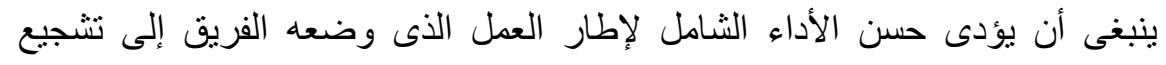

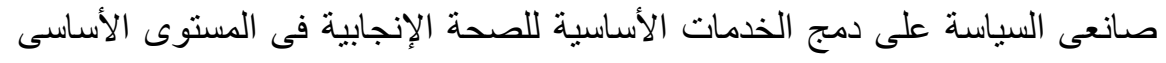

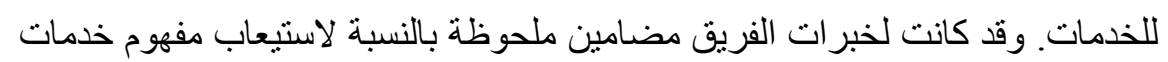
الرعاية الأساسية وطريقة تقديمها فى البلدان النامية.

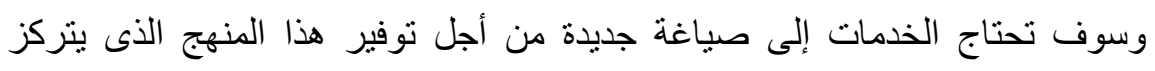

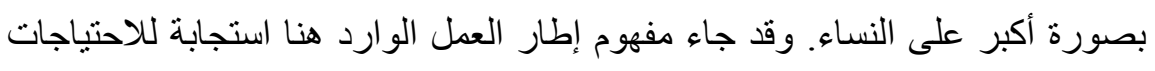

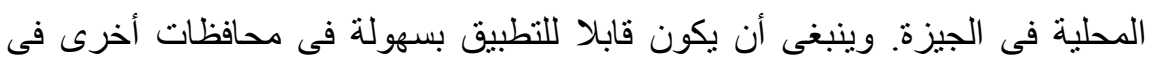

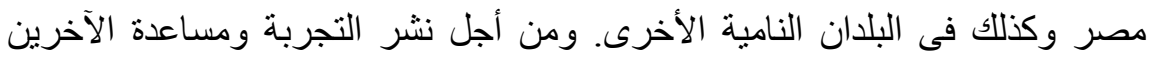

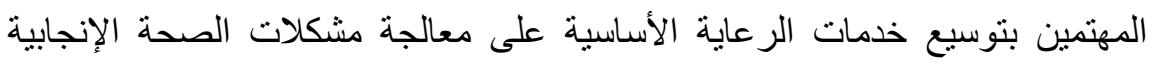

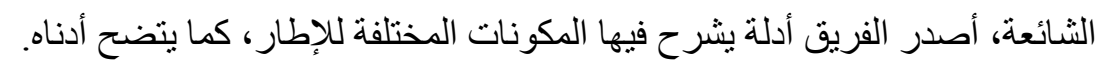
وتعتبر المضامين الخاصة بالتدريب على جانب كبير من الأهمية. و إذا أخذت هذه الأهن

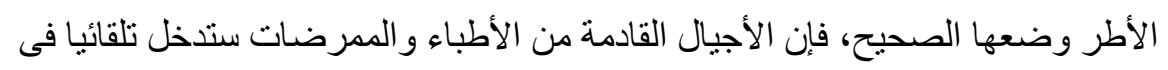

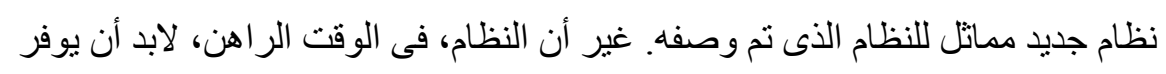

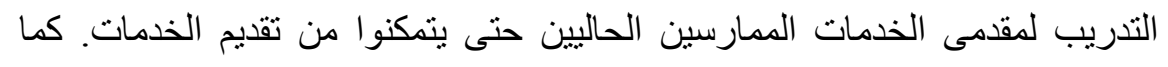

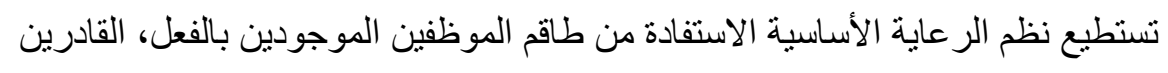

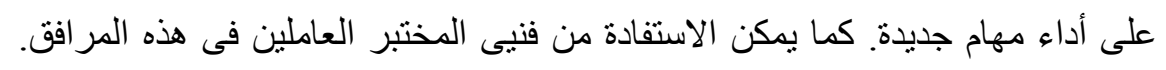

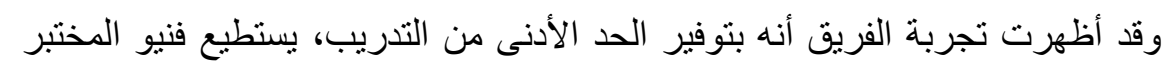

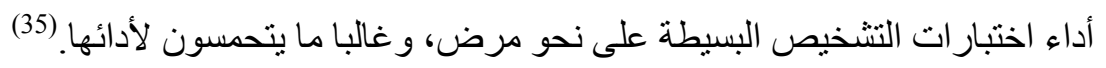

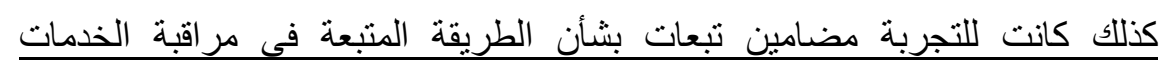

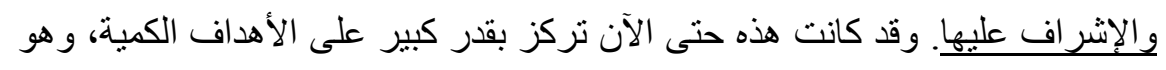

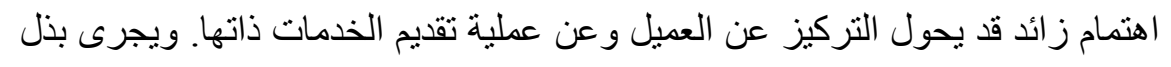

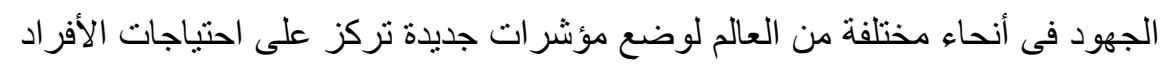
(35) تؤيد نتائج مماثلة الأداء المرضى للفنيين على هذا المستوى بعد تلقى التدريب الأساسى. خان، ام. أى.، وآخرون (1998). 
و على جودة الخدمات. وسوف تحتاج النظم إلى التكيف من أجل الاستفادة من المناهج

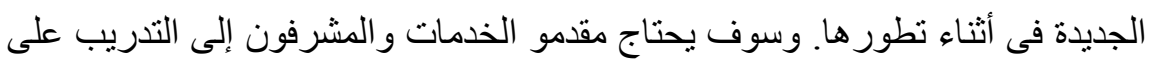

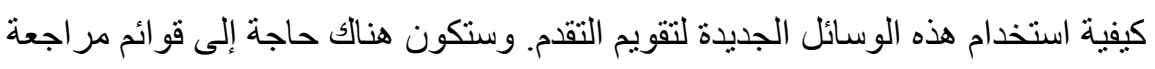

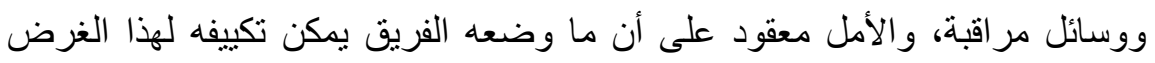

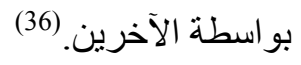

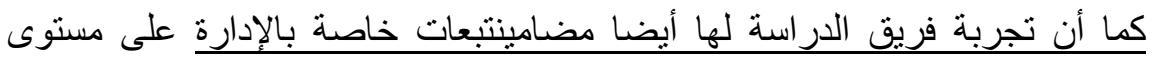
المركز الصحى. وقد أوضحت المراجعة التى أجراها المؤتمر الدولى للسكان والتنمية

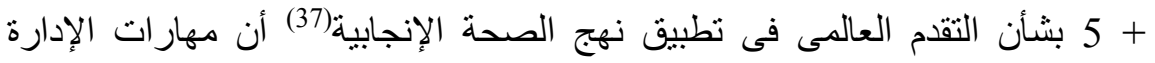

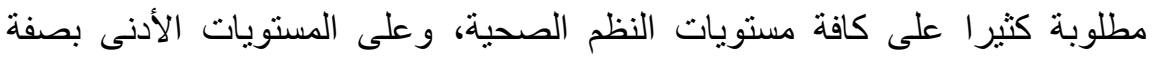

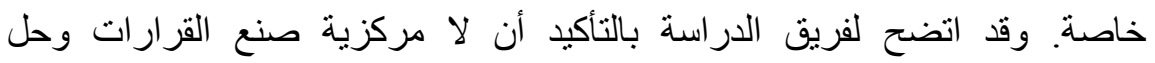

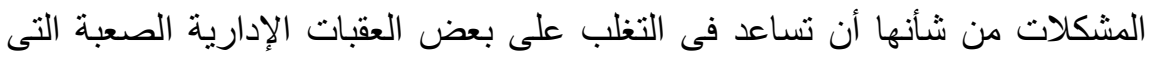
تواجه تقديم الخدمات. كما أن المزيد من المرونة فى تخصيص اعلى الموارد ومدخلات

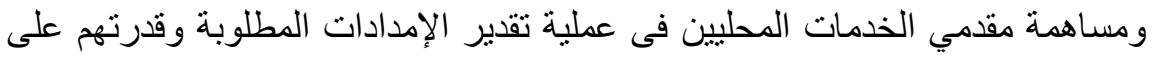
تتظيم مسائل الصيانة، من شأنه أن يسهم بقدر كبير فى حل المه الثكلات البسيطة،

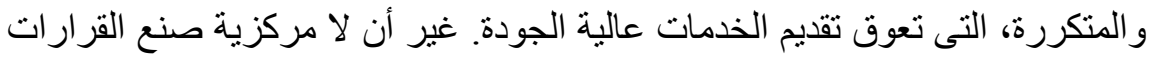

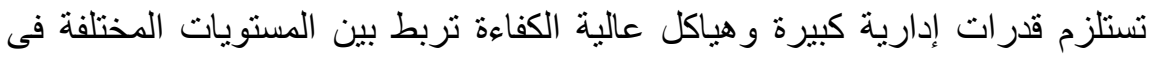
داخل النظام. وبينما تشير الثواهد العالمية (انظر المصدر السابق) إلى أن نجاح جهود

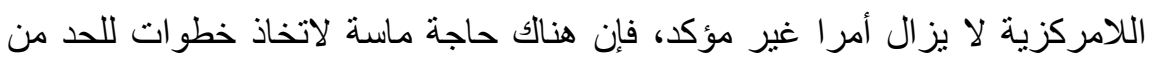
العقبات البيروقر اطية إلى أقصى درجة ممكنة.

وتمر مصر حاليا بمرحلة التخطيط لإصلاحات واسعة النطاق فى قطاعها الصحى التى ستتضمن قدر ا من اللامركزية. والأمل معقود على أن تحظى الصحة الإنجابية بأولوية لئل

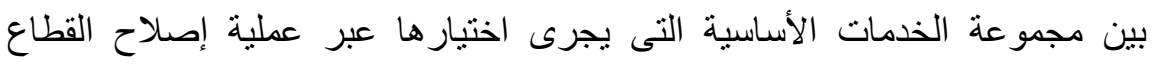

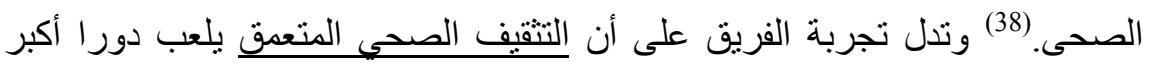
كبير آ فى زيادة الوعى الصحى. ويوصى بوسائل التدريب بالمشاركة.

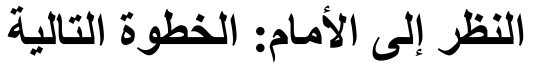

يقوام الفريق حاليا بتوسيع نطاق تجربته لتشمل عددا أكبر من المراكز الصحية. وتتضمنت هذه المرحلة 15 موقعا فى الجيزة لتقديم الخدمات، وذلك بناء على اقتراح وزارة الصحة والسكان. ويتولى إخصائيون على مستوى الإدارة الصحية مهمة 
المدربين التدريب فى مختلف جوانب إطار العمل. وتتضمنت مرحلة التوسع تدريب مقدمى الخدمات على مستوى المركز الصحى، وكذلك تدريب المشرفين على مستوى ولنى الإدارة الصحية على وسائل المراقبة التى وضعها الفريق. وفى حين أنى أنى تجربة الفريق ولثي

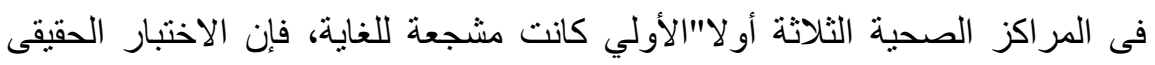
لأداء إطار العمل يكمن فى تقييم المرحلة التالية.

أدلة أعدتها دراسة تدخل

الصحة الإنجابية

دليل الارتقاء بوحدات الر عاية الصحية الأساسية

دليل عمل الأطباء العاملين فى الرعاية الصحية الأساسية - خدملات الهاتهاتهاتهات الصحة الإنجابية

دليل تدريب أطباء الرعاية الصحية الأساسية

دليل عمل لممرضات وحدات الرعاية الصحية الأساسية

دليل عمل لممرضات وحدات الرعاية الصحية الأساسية- ـ للزيارات المنزلية

دليل نظام الإحالة لأمراض الصحة الإنجابية بوحدات الرعاية الصحية الأساسية

دليل عمل الفنى المعمل العاملين بوحدات الرعاية الصحية الأساسية ـ خدمات الصحة الإنجابية

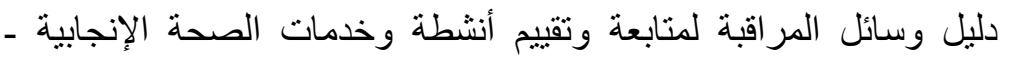
بوحدات الرعاية الصحية الأساسية دليل مؤشر ات خدمات الصحة الإنجابية بوحدات الرعاية الصحية الأساسية دليل التثقيف الصحي - رسائل صحية موجهة للمر أة دليل التثقيف الصحي - رسائل صحية موجهة للرجال دليل مشاركة المجنمع المحلى فى الرعاية الصحية الأولية 
Catino, J. (1999). Meeting the Cairo Challenge: Progress in Sexual and Reproductive Health. Implementing the ICPD Program of Action. Family Care International.

Chowdhury, S.N.M., Y.H. Ahmed, E. Karim, A.E. Masum. (1995). “A

Study to Determine the Prevalence of Reproductive Tract Infections

Among Health Care Users of a Bangladesh Women ${ }^{\mathrm{TM}_{\mathrm{S}}}$ Health Coalition

Clinic" BWHC, Dhaka, Bangladesh.

El-Adawy, M and K. Khalil. (1998). "An Overview of Health Reform in

the MENA Region: The Rationale for Including Reproductive Health

Services" Q . Background paper for Population Challenges in the Middle

East and North Africa: Towards the 21 st Century, Workshop organised by

the Economic Research Forum, Cairo, November 1998.

El-Zanaty, F., E. M. Hussein, G. A. Shawky, A. A. Way, and S. Kishor. (1996). Egypt Demographic and Health Survey (EDHS) 1995. Calverton, Maryland [USA]: National Population Council [Egypt] and Macro International Inc.

Elias, C. (1996). “A Puzzle of Will: Responding to Reproductive Tract

Infections in the Context of Family Planning Programs". Social Change.

September-December 1996: Vol. 26 No. 3-4.

Fathalla, M. F. (1991). "Reproductive Health: A Global Overview".

Annals of New York Academy of Sciences. Vol. 1, P. 1-10.

Fortney, J. A. (1995). "Reproductive Morbidity: A Conceptual

Framework". Family Health International- Working Papers. Sept. No.

WP95-02.

Hardee, K. and K. Yount. (1995). From Rhetoric to Reality: Delivering

Reproductive Health Promises Through Integrated Services. Family

Health International Working Papers.

Hardee, K., K. Agarwal, N. Luke, E. Wilson, M. Pendzich, M. Farrell

and H. Cross. (1999). "Reproductive health policies in Eight Countries:

Progress Since Cairo". International Family Planning Perspectives, Vol.

25, Supplement, p. S2-S9.

Hussain, M.A., G.S. Rahman, N.G. Banik, N. Begum. (1996). “A Study

on Prevalence of RTI/STDs in a Rural Area of Bangladesh," Save the

Children (USA). Dhaka

Khan, M., S. R. Rao, R.B. Gupta, B. Patel, L. Caleb, J. Tuladhar and J.

Townsend. (1998). "Integrating RTI services in primary health care

system: observations from an operations research in Uttar Pradesh, 
India". Improving Reproductive Health: International Shared

Experience (Proceeding of a two-day International Workshop in Bogor, West Java, December 4-5, 1997). Jakarta: The Population Council. p. 169-186.

Khattab, H., K. Khalil and N. Younis. (1996). " Socio-medical Dimensions of Women ${ }^{\mathrm{TM}_{\mathrm{S}}}$ Utilization of Reproductive Health Services in Giza, Egypt". Proceedings of the Arab Regional Population Conference in Cairo, December 8-12, Vol. 3. Liege: International Union for the Scientific Study of Population, p. 101-122.

Khattab, H., M. Geneidy and N. Karraz Shorbagi. (1999). Health

Education as a Component of Health Promotion. Intervention Study Policy Paper.

Khattab, H., O. Kamal, A.M. Farag and N. Abou-Seoud. (2000). Nurses Outreach Manual for Primary Health Care. Reproductive Health Intervention Study Manuals. Cairo, 2000.

Mamdani, M. (1999). "Management of Reproductive Tract Infections in Women: Lessons From the field". In Saroj Pachauri and Sangeeta Subramanian (eds.) Implementing a Reproductive Health Agenda in India: The Beginning. New York: The Population Council, p. 435-505. Tsui, A. et al., eds., Reproductive Health in Developing Countries: Expanding Dimensions, Building Solutions (Washington, DC: National Academy Press, 1997).

Pachauri, S. (1995). Defining a Reproductive Health Package for India: A Proposed Framework. Regional Working Papers, No. 4, The Population Council.

Wasserheit, J. (1989). "The Significance and Scope of Reproductive Tract infections Among Third World Women". International Journal of Obstetrics and Gynecology. Supplement 3 (1989): 145-68.

Younis, N., Khattab, H., Zurayk, H., El-Mouelhy, M., Fadel Amin, M., and Farag, A.M. (1993). "A Community Study of Gynecological and Related Morbidities in Rural Egypt” Studies in Family Planning, Vol. 24, no. 3, pp.175-186. 


\section{ملحق 1: الملف الطبى}

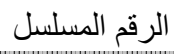

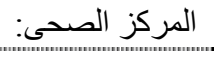

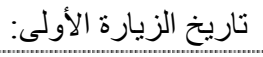
السن: الاسم: - لمابح العنوان.......

عدد مر ات الإجهاض: عدد المو اليد الأحياء: عدد مر ات الو لادة.

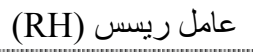

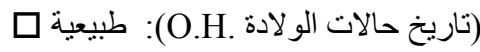
نوع الو لادات السابقة: بالمساعدة ه قيصرية تاريخ حالات الو لادة (التاريخ السابق) تاريخ التحويل: - ت

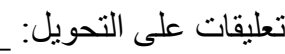
تقييم الحمل الحالى:

\section{رعاية الحمل}

التاريخ المنتظر للولادة: تاريخ آخر دورة شهرية:

\begin{tabular}{|c|c|c|c|c|c|c|c|c|c|c|c|c|}
\hline |لعلاحظات/ & |"التحويل |- & |ككر الدم & تلبليل & |نهينوجئو| بئم| & |الجنين & الجنيض & |ارتفتوع & الأطرافئ & الوزن & |الدم & الشكوى & التتاريخ \\
\hline & & & & & & & & & & & & \\
\hline & & & & & & & & & & & & \\
\hline & & & & & & & & & & & & \\
\hline & & & & & & & & & & & & \\
\hline & & & & & & & & & & & & \\
\hline & & & & & & & & & & & & \\
\hline
\end{tabular}

تاريخ التحويل: تعليقات على التحويل: متابعة فترة النفاس تقييم الحمل الحالى: تصلئ: نوع الو لادة: تاريخ الو لادة: من وجد فى أثناء الو لادة:

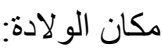

\begin{tabular}{|c|c|c|c|c|c|c|c|c|c|}
\hline ملاحظظات & اختبارات & الطبيعية & الثّى & الرضيع & ضغط الدام & الحرارة & الرتفاع & الثشكوى & التاريخ \\
\hline & & & & & & & & & \\
\hline & & & & & & & & & \\
\hline & & & & & & & & & \\
\hline & & & & & & & & & \\
\hline & & & & & & & & & \\
\hline & & & & & & & & & \\
\hline
\end{tabular}




\begin{tabular}{|c|c|c|c|c|c|c|c|c|c|c|c|c|c|c|}
\hline \multicolumn{14}{|c|}{ الصحــة الإنجابيـة } & \multirow[b]{3}{*}{ تاريخة } \\
\hline \multicolumn{4}{|c|}{ العلاج و المتابعة } & \multicolumn{6}{|c|}{ الفحص } & \multicolumn{4}{|c|}{ التاريخ المرضى الحالى } & \\
\hline ملاحظابعة & الإحالة & المتظيلة & العلاج & تثخيص & فعطى & المهبلى & الأعضاط & الثذى & ضنط & المسيلة تنظيم & الإقرازات & 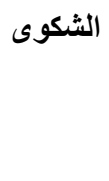 & الآخيض & \\
\hline & & & & & & & & & & & & & & \\
\hline & & & & & & & & & & & & & & \\
\hline & & & & & & & & & & & & & & \\
\hline & & & & & & & & & & & & & & \\
\hline & & & & & & & & & & & & & & \\
\hline & & & & & & & & & & & & & & \\
\hline & & & & & & & & & & & & & & \\
\hline & & & & & & & & & & & & & & \\
\hline & & & & & & & & & & & & & & \\
\hline
\end{tabular}


